\title{
Documento orientador da ABENO para qualidade dos cursos de graduação em Odontologia
}

Organização: Maria Celeste Morita; Ana Isabel Fonseca Scavuzzi; Daniela Lemos Carcereri; Vania Regina Camargo Fontanella

\section{Colaboradores:}

Ana Estela Haddad; Armando Hayassy; Celso Zilbovicius; Claudio José Amante; Elaine Bauer Veeck; Elisa Emi Tanaka Carloto; José Galba de Menezes Gomes; José Ranali; José Tadeu Pinheiro; Léo Kriger; Lino João da Costa; Luiz Augusto Noro; Maria Ercília de Araújo; Mário Uriarte Neto; Raquel Sano Suga Terada; Rui Barbosa de Brito Junior. 


\section{APRESENTAÇÃO}

O Sistema Nacional de Avaliação da Educação Superior - SINAES, instituído pela Lei n ${ }^{\circ}$ 10.861/2004, tem por finalidades a melhoria da qualidade da educação superior, a orientação da expansão da sua oferta, o aumento permanente da sua eficácia institucional e efetividade acadêmica e social e, especialmente, a promoção do aprofundamento dos compromissos e responsabilidades sociais das Instituições de Educação Superior, por meio da valorização de sua missão pública, da promoção dos valores democráticos, do respeito à diferença e à diversidade, da afirmação da autonomia e da identidade institucional. A qualidade dos cursos de graduação em Odontologia é evidenciada pelas condições de ensino oferecidas aos estudantes, em especial aquelas relativas à organização didático-pedagógica, ao perfil do corpo docente e às instalações físicas.

A Associação Brasileira de Ensino Odontológico - ABENO, instituição fundada em 1956, tem como missão promover a excelência na formação em Odontologia. Sua história descreve uma longa trajetória de parcerias com os órgãos públicos com os quais seus objetivos convergem. Nesse sentido participou das comissões de especialistas do Provão e dos processos de avaliação das condições de ensino nos anos 90 e posteriormente das Comissões assessoras do Enade e dos processos de avaliação in loco empreendidos no âmbito do SINAES.

Compreendendo os processos de avaliação como indutores de qualidade da Educação Superior, o Instituto Nacional de Pesquisas Institucionais - INEP firmou em 2013 uma parceria com a ABENO, com vistas a aperfeiçoar a formação de avaliadores nesta área de conhecimento. Para consecução de tal objetivo, o INEP e a ABENO realizaram uma formação continuada dirigida aos avaliadores do Basis/Odontologia para discussão de um documento orientador, à época em construção. Em 2013, o documento preliminar para uso na formação de avaliadores visava à compreensão do instrumento de avaliação in loco nas especificidades referentes à área de Odontologia para as Instituições de Educação Superior - IES e os avaliadores, dando subsídios para todo o processo avaliativo, assegurando a transparência, a manutenção dos princípios do SINAES, que preveem o instrumento como principal indutor da qualidade. Desde então a ABENO reestruturou esse documento preliminar sucessivas vezes já que os instrumentos de referência passaram por diversas mudanças e a qualidade dos cursos de graduação em Odontologia precisa ser garantida.

Nos últimos anos, ocorreu um aumento exponencial do número de cursos de graduação em Odontologia no Brasil, tornaram-se mais evidentes as fragilidades que o SINAES apresenta para identificar a qualidade da oferta e expansão desses cursos. Nessa perspectiva a ABENO, consciente de seu papel e missão de promover a qualidade da educação odontológica, apresenta esse documento para orientar as IES e avaliadores de cursos de graduação em Odontologia, subsidiar a construção de relatórios, e em última instância transferir para a sociedade sua expertise construída ao longo de mais de sessenta anos de experiência no ensino odontológico.

Maria Celeste Morita, presidente da ABENO

Brasília, 13 de julho de 2018. 


\section{INFORMAÇÕES IMPORTANTES SOBRE O PRESENTE DOCUMENTO}

No contexto da educação superior, a flexibilização preconizada pela Lei de Diretrizes e Bases da Educação Nacional (LDB, 1996), confere às Instituições de Educação Superior novos graus de liberdade que possibilitam o desenho de currículos inovadores, adequados às realidades regionais e às respectivas vocações das escolas. Conforme a LDB, a Educação Superior tem por finalidade, entre outros, formar diplomados nas diferentes áreas de conhecimento, aptos para a inserção em setores profissionais e para a participação no desenvolvimento da sociedade brasileira, e colaborar na sua formação contínua; estimular o conhecimento dos problemas do mundo presente, em particular os nacionais e regionais, prestar serviços especializados à comunidade e estabelecer com esta uma relação de reciprocidade (LDB, 1996).

As orientações apresentadas neste Documento Orientador compreendem as especificidades do curso de graduação em Odontologia a serem evidenciadas na análise de cada indicador de qualidade. A qualidade da oferta do ensino odontológico na graduação será garantida por meio das evidências apresentadas nos documentos institucionais e do próprio curso, pelas ações adotadas e institucionalizadas no âmbito do curso, pela estrutura física disponível para o desenvolvimento das atividades e pelo discurso dos atores envolvidos na proposição e/ou na realização do curso.

Um conjunto de documentos e evidências serão elencados nas orientações específicas para cursos de graduação em Odontologia em cada um dos indicadores deste Documento Orientador. Neste cenário, a IES precisa conceber e institucionalizar qualitativamente cada um deles, evidenciando coerência na realidade descrita nos documentos institucionais e na realidade praticada pelo curso de graduação em Odontologia. Esta construção coletiva, ou seja, envolvendo todos os atores relacionados ao curso ofertado, documentada e comprovada por meio das evidências da realidade praticada pela IES, definirão a qualidade das condições de oferta do curso de graduação em Odontologia.

\subsection{ORGANIZAÇÃO DIDÁTICO-PEDAGÓGICA DO CURSO DE GRADUAÇÃO EM ODONTOLOGIA}

Na Organização Didático-Pedagógica dos cursos de graduação em Odontologia, o PDI e o PPC são documentos essenciais e obrigatórios, de modo que esclareçam os princípios que promovem a organização do curso. Assim, o conjunto de conhecimentos que compõe a organização didáticopedagógica deverá propiciar o cumprimento dos objetivos - desenvolvimento de habilidades e competências - em conformidade com o perfil do egresso definido no PPC e com as políticas institucionais estabelecidas no PDI.

\section{Políticas institucionais no âmbito do curso}

As políticas institucionais no âmbito do curso de graduação em Odontologia devem prever a articulação de ações, atividades de ensino, extensão e pesquisa/iniciação científica, de acordo com a organização acadêmica da IES.

A pesquisa, quando prevista no PPC, e a extensão são mecanismos de apoio ao desenvolvimento da formação que devem estar explícitos por meio de ações e atividades pedagógicas, como nas 
modalidades de monitoria, extensão, iniciação científica e demais mecanismos concretos para favorecer esta formação, incluindo políticas de apoio à permanência estudantil.

As políticas institucionais constantes no PDI devem estar claramente integradas ao PPC. As evidências de que tais políticas estão efetivamente implantadas no âmbito do curso, com envolvimento direto de alunos e professores nas ações supramencionadas são indispensáveis.

Em relação às políticas institucionais, o aprendizado deve ter como referência a construção do conhecimento e a realidade de vida das pessoas; a pesquisa deve estar articulada com os principais problemas de saúde bucal da população e a extensão deve ser desenvolvida como estratégia de aprendizado e interação com a comunidade, servindo como instrumento de construção de cidadania.

\section{DOCUMENTOS NECESSÁRIOS:}

$\checkmark$ DCN dos cursos de graduação em Odontologia;

$\checkmark$ PDI;

$\checkmark$ PPC;

$\checkmark$ Projetos e iniciativas do curso;

$\checkmark$ Convênios e parcerias firmados;

$\checkmark$ Políticas de apoio e permanência estudantil.

\section{EVIDÊNCIAS PARA COMPROVAÇÃO:}

$\checkmark$ Impacto das políticas institucionais na construção e desenvolvimento do PPC;

$\checkmark$ Ações de ensino, extensão e pesquisa (quando for o caso) no âmbito do curso em correspondência com o grau de formação do cirurgião-dentista descrito no PPC;

$\checkmark$ Adoção de práticas comprovadamente exitosas ou inovadoras para revisão destas políticas no âmbito do curso.

\section{Objetivos do curso}

Para definição dos objetivos do curso, o perfil profissional definido no PPC deve estar em conformidade com as DCN dos cursos de graduação em Odontologia, com a estrutura curricular, com a existência de componentes curriculares que contemplem as competências e habilidades gerais e específicas, além do contexto educacional loco regional no qual se insere o curso.

Os objetivos do curso devem contemplar o contexto educacional e suas demandas de natureza econômica e social descritos no PPC e, necessariamente, devem contemplar o envolvimento do curso com o Sistema Único de Saúde (SUS).

Como contexto educacional a IES deve demonstrar, por meio de seu PDI, que tem conhecimento das demandas sociais da comunidade e que o curso de graduação em Odontologia é uma de suas atividades para direcionar suas ações em benefício das necessidades socioeconômicas locais e regionais.

Para tanto, é necessário constar no PPC um diagnóstico situacional claro, fundamentado, referendado e baseado em dados oficiais (mapeamento, demandas, acompanhamento, soluções propostas de acordo com a realidade local e regional), assim como a necessária comprovação de evidências junto aos atores. É importante levar em conta o perfil epidemiológico de doenças bucais, a capacidade instalada dos serviços de saúde, e o potencial do curso de graduação em Odontologia na melhoria das condições de saúde e da qualidade de vida da população.

Em síntese, a concepção do PPC, em consonância com o contexto educacional, deve expressar a parceria com os gestores do SUS; preocupação e adequação da formação de profissionais para atender às necessidades loco regionais, com ampliação da atenção à saúde e a capacidade de absorção dos egressos na área de influência da região. 
O contexto educacional do curso de graduação em Odontologia deve considerar as necessidades da região de saúde e/ou do município e os mecanismos de inserção e articulação com as políticas públicas do SUS, o que implica na definição de onde se instalam os cenários de prática os quais podem ocorrer no campus da IES ou na região onde esta se insere.

Isso implica considerar que, na avaliação de cursos na área de saúde, tanto estes aspectos quanto as demandas efetivas de natureza econômica, social, cultural, política e ambiental compõem o contexto educacional.

\section{DOCUMENTOS NECESSÁRIOS:}

$\checkmark$ Censo da Educação Superior;

$\checkmark$ Censo populacional (IBGE);

$\checkmark$ Convênios firmados pela IES/ curso de graduação em Odontologia;

$\checkmark$ Dados do último levantamento epidemiológico em saúde bucal para a região;

$\checkmark$ DCN dos cursos de graduação em Odontologia;

$\checkmark$ Parecer do Conselho Municipal de Saúde;

$\checkmark$ PDI;

$\checkmark$ PPC;

$\checkmark$ Planos de ensino;

$\checkmark$ Projetos e iniciativas do curso.

\section{EVIDÊNCIAS PARA COMPROVAÇÃO:}

Coerência dos objetivos do curso em relação à integração curricular, à multidisciplinaridade, à interprofissionalidade e à universalidade da formação;

$\checkmark$ Coerência entre os objetivos do curso, o perfil profissional descrito nas DCN do curso de graduação em Odontologia, a estrutura curricular proposta e o contexto educacional loco regional;

$\checkmark$ Relação entre os objetivos do curso e a integração social na comunidade local e regional, a existência documental de parcerias, convênios, projetos ou iniciativas institucionais consolidadas;

$\checkmark$ Atividades didáticas descritas no PPC com objetivos e metas claras para atingir um perfil profissional que seja capaz de transformar a realidade local e regional (apresentando relação do perfil às soluções aos problemas detectados);

$\checkmark$ Necessidades da região de saúde e/ou do município e os mecanismos de inserção e articulação com as políticas públicas do SUS descritos no PDI/PPC;

$\checkmark$ A Saúde Coletiva, a integração ensino-serviços e comunidade como eixos estruturantes da matriz curricular, com objetivo de aproximação com a realidade;

$\checkmark$ Análise inicial da situação e a formação convergentes para um profissional adequado à realidade local, contempladas nos conteúdos das disciplinas ou módulos da estrutura curricular do curso de graduação em Odontologia;

$\checkmark$ Concepção do PPC em parceria com os gestores do SUS

$\checkmark$ Novas práticas emergentes no campo do conhecimento relacionado à Odontologia. 


\section{Perfil profissional do egresso}

O perfil profissional almejado para o curso descrito no PPC deve estar consonante com as competências gerais e específicas a serem desenvolvidas de acordo com as DCN dos cursos de graduação em Odontologia e, ao mesmo tempo, deve preservar a sua própria identidade, atender o contexto educacional, e ser resultado do cumprimento dos objetivos do curso.

O perfil do egresso do curso de graduação em Odontologia deverá contemplar as seguintes características:

I. Cirurgião-Dentista Generalista, dotado de sólida formação técnico-científica e ativo na construção permanente de seu conhecimento;

II. Humanístico e ético, atento à dignidade da pessoa humana, e às necessidades individuais e coletivas, promotor da saúde integral, e transformador da realidade em benefício da sociedade;

III. Apto à atuação em equipes de forma interprofissional, interdisciplinar e transdisciplinar;

IV. Proativo e empreendedor, com atitude de liderança;

V. Comunicativo, capaz de se expressar com clareza;

VI. Crítico, reflexivo e atuante na prática odontológica em todos os níveis de atenção à saúde;

VII. Consciente e participativo frente às políticas sociais, culturais, econômicas e ambientais e às inovações tecnológicas.

Este perfil é confirmado por meio da estrutura curricular que deve ser caracterizada pela integração curricular dos seus componentes e atendimento às competências gerais e específicas descritas nas DCN dos cursos de graduação em Odontologia, caso contrário, o perfil descrito no PPC não tem coerência com as competências propostas.

\begin{tabular}{|c|c|}
\hline $\begin{array}{l}\text { DOCUMENTOS NECESSÁRIOS: } \\
\checkmark \text { PPC; } \\
\checkmark \text { DCN dos cursos de graduação em Odontologia; } \\
\checkmark \text { Política institucional de acompanhamento dos } \\
\text { egressos descrita no PDI e mecanismos de } \\
\text { acompanhamento dos egressos na sua atuação } \\
\text { profissional descritos no PPC; } \\
\checkmark \text { Perfil profissional contemplando competências e } \\
\quad \text { habilidades que correspondem às intervenções } \\
\quad \text { profissionais dos egressos do curso de graduação } \\
\text { em Odontologia. } \\
\checkmark \text { Políticas de acompanhamento dos egressos; } \\
\checkmark \\
\text { Relatórios de acompanhamento dos egressos. }\end{array}$ & $\begin{array}{l}\text { EVIDÊNCIAS PARA COMPROVAÇÃO: } \\
\checkmark \text { Consonância entre o perfil profissional definido } \\
\text { no PPC e as DCN dos cursos de graduação em } \\
\text { Odontologia, a realidade local e regional, } \\
\text { preservando a identidade e a especificidade do } \\
\text { curso; } \\
\checkmark \text { Coerência entre o perfil descrito no PPC, os } \\
\text { objetivos e a estrutura curricular do curso; } \\
\checkmark \text { Mecanismos de apropriação do PPC pelo corpo } \\
\text { docente e pelo discente; } \\
\checkmark \text { Ampliação do perfil em função de novas } \\
\text { demandas apresentadas no mundo do trabalho do } \\
\text { cirurgião-dentista; } \\
\checkmark \text { Eventos com participação dos egressos. }\end{array}$ \\
\hline
\end{tabular}

\section{Estrutura curricular}

A estrutura curricular deve atender às DCN dos cursos de graduação em Odontologia na qual deverá estar clara a existência de eixos temáticos/ núcleos curriculares/ unidades curriculares que contemplem a formação geral, formação profissional e a cidadania. Deverá se caracterizar pela integração curricular, interdisciplinaridade, flexibilidade, compatibilidade de carga horária e articulação entre teoria e prática. 
A estrutura curricular do curso de graduação em Odontologia deverá ter como eixo do desenvolvimento as necessidades de saúde dos usuários e das populações, incluindo as dimensões ética, humanística e sociais, orientados para a cidadania ativa multicultural e para os direitos humanos, tendo as Ciências Humanas e Sociais como eixo transversal na formação do profissional.

A estrutura do curso de graduação em Odontologia deverá aproximar o conhecimento básico da sua aplicação clínica, por meio da integração curricular, desenvolvida por meio de currículo integrado baseado na interdisciplinaridade e na articulação entre as dimensões sociais, biológicas, odontológicas, culturais, ambientais, étnicas e educacionais.

A integração dos conteúdos e práticas dos componentes curriculares deve ser apoiada e consolidada por meio de um processo de educação permanente previsto na formação docente institucional.

O curso deverá incluir a utilização de metodologias ativas de aprendizagem, em busca de um aprendizado significativo pelos estudantes, de forma que contemple mecanismos de flexibilidade e privilegiem a participação do estudante na construção do conhecimento.

O processo de ensino-aprendizagem, quando envolver atendimento a usuários, deve consolidarse no cuidado integral e resolutivo, como processo único e contínuo, seja na clínica-escola ou nos cenários dos serviços de saúde.

Quanto à interdisciplinaridade, importa que a estrutura curricular proposta contemple conteúdos interdisciplinares em mais de um período do curso (ver definição de INTERDISCIPLINARIDADE no Glossário dos Instrumentos de Avaliação Externa do INEP - 2018).

Quanto à flexibilidade, importa que a carga horária atribuída na estrutura curricular contemple componentes curriculares obrigatórios inclusive estágios supervisionados e componentes curriculares não obrigatórios, como atividades complementares ao ensino, componentes curriculares optativos ou eletivos que possam ser escolhidos pelos alunos. A disciplina de Libras deve ser oferecida como optativa.

Quanto à compatibilidade de carga horária dos componentes curriculares, importa que a mesma atenda à legislação acerca da duração da hora-aula (Resolução CNE/CES n. 02/2007) e (Resolução CNE/CES n. 04/2009). Para a adequada formação preconizada pelas DCN dos cursos de graduação em Odontologia e atendendo a parâmetros internacionais será necessário contemplar na estrutura curricular carga horária prática, no mínimo, de 55\% da carga horária total do curso, incluindo conteúdos curriculares que correspondem às áreas básicas, sendo que a carga horária de atividades clínicas de atenção ao paciente, não poderá ser inferior a $40 \%$ da carga horária total do curso.

Em relação à extensão, observar a implantação de, no mínimo, 10\% da carga horária do curso, de acordo com a meta 12.7 do PNE (Lei N ${ }^{\circ} 13.005$, de 25 de junho de 2014). De acordo com a lei, a implantação deste percentual é progressiva e deverá estar totalmente implantado em 2024.

Quanto à articulação entre teoria e prática, importa que a carga horária teórica e prática para os conteúdos básicos e profissionalizantes, previstos na estrutura curricular do curso de graduação em Odontologia seja compatível com os objetivos do curso e com o perfil profissional descrito no PPC, necessariamente deve contemplar uma carga horária que caracterize o envolvimento do curso com o SUS.

Quanto à ACESSIBILIDADE METODOLÓGICA consultar a definição no Glossário dos Instrumentos de Avaliação Externa do INEP - 2018. 
A flexibilização curricular deve ser levada em conta. Além disso, para que a estrutura curricular seja plenamente desenvolvida, são necessários recursos de infraestrutura e de comunicação nos quais está implícita a necessidade de remoção de barreiras arquitetônicas, digitais e nas comunicações.

\section{DOCUMENTOS NECESSÁRIOS:}

$\checkmark \quad \mathrm{PPC}$;

$\checkmark$ DCN dos cursos de graduação em Odontologia;

$\checkmark$ Resolução CNE/CES n. 02/2007 e Resolução CNE/CES n. 04/2009;

$\checkmark$ Resolução 350/CNS/2005;

$\checkmark$ Estrutura curricular cadastrada no sistema da instituição;

$\checkmark$ Histórico escolar de egressos e correspondência com estrutura curricular cadastrada no sistema da IES.

\section{EVIDÊNCIAS PARA COMPROVAÇÃO:}

$\checkmark$ Quanto à interdisciplinaridade: estrutura curricular proposta e a existência de conteúdos interdisciplinares em mais de um período do curso (ver conceito de Interdisciplinaridade no Glossário dos Instrumentos de Avaliação Externa do INEP - 2018);

$\checkmark$ Quanto à flexibilidade: existência de uma carga horária atribuída na estrutura curricular que contemple componentes curriculares obrigatórios inclusive estágios supervisionados e componentes curriculares não obrigatórios, como atividades complementares ao ensino, componentes curriculares optativos ou eletivos que possam ser escolhidos pelos alunos;

$\checkmark$ Quanto à compatibilidade de carga horária: a carga horária dos componentes curriculares e o atendimento à legislação acerca da duração da hora ou a existência de atividades de aprendizagem que caracterizem a integração desta carga horária conforme prevê esta legislação. Os cursos de Odontologia devem respeitar a carga horária mínima de quatro mil horas (4.000h) e deve-se observar a coerência com o número de períodos e carga horária diária/semanal, especialmente aqueles cursos com propostas em tempo parcial;

$\checkmark$ Quanto à distribuição da carga horária: carga horária prática correspondente no mínimo a 55\% da carga horária total (em horas) do curso, incluindo áreas básicas, sendo que a carga horária de atividades clínicas de atenção ao paciente deve corresponder no mínimo a $40 \%$ da carga horária total (em horas) do curso;

$\checkmark$ Quanto à articulação teoria e prática: a carga horária prática prevista na estrutura curricular do curso e a coerência desta carga horária proposta com os objetivos do curso e com o perfil profissional descrito no PPC; compatibilidade entre a articulação da carga horária prática prevista com a carga horária teórica do curso, aproximando conhecimento básico da sua utilização clínica; viabilização pela integração e articulação entre os componentes curriculares;

$\checkmark$ Quanto à acessibilidade metodológica: observar as definições no Glossário dos Instrumentos de Avaliação Externa do INEP - 2018;

$\checkmark$ Estrutura curricular organizada com ousadia de inovação na perspectiva da formação em equipe de saúde, com práticas de educação por métodos ativos e de educação permanente, entre outros. 


\section{Conteúdos curriculares}

Os conteúdos essenciais do curso de graduação em Odontologia deverão estar relacionados com o processo saúde-doença do indivíduo, da família e da população, nos diferentes ciclos de vida, referenciados na realidade epidemiológica e profissional, e serão compostos por conteúdos das Ciências Biológicas e da Saúde, das Ciências Humanas e Sociais e das Ciências Odontológicas, os quais devem estar interligados, desenvolvidos de maneira integrada, visando ao cuidado integral do indivíduo.

Os componentes curriculares vinculados à formação profissional da Odontologia e seus conteúdos teóricos, prático, laboratoriais, clínicos e de estágios com ênfase nas áreas préprofissionalizantes e profissionalizantes das Ciências Odontológicas, inclusive Saúde Bucal Coletiva, devem ser ministrados nos cursos de graduação em Odontologia exclusivamente sob a modalidade presencial (Resolução CFO 186/2017).

As atividades didáticas devem inserir o estudante nas redes de serviços do SUS ao longo do Curso de Graduação em Odontologia, permitindo ao estudante conhecer e vivenciar as políticas de saúde em situações variadas de vida, de organização da prática e do trabalho da equipe interprofissional, oportunizando aprendizado no SUS.

Nas Ciências Biológicas e da Saúde, incluem-se os conteúdos teóricos e práticos de base bioquímica, molecular, morfológica, celular e tecidual dos processos normais e alterados de forma integrada, e da estrutura e função dos tecidos, órgãos, sistemas e aparelhos, aplicados às situações decorrentes do processo saúde-doença, no desenvolvimento da prática assistencial de Odontologia para a atenção integral à saúde.

Nas Ciências Humanas e Sociais incluem-se os conteúdos teóricos e práticos referentes:

I. Às diversas dimensões da relação indivíduo/sociedade, contribuindo para a compreensão dos determinantes sociais, culturais, comportamentais, psicológicos, ecológicos, éticos, bioéticos e forenses, nos níveis individual e coletivo, do processo saúde-doença;

II. À Saúde Coletiva como sustentação longitudinal ao aprendizado, à investigação e às práticas dos estudantes a partir do conhecimento de promoção da saúde, políticas públicas de saúde, epidemiologia, ciências sociais e planejamento e gestão de serviços de saúde, considerando os determinantes sociais da saúde;

III. Às políticas de educação e sustentabilidade ambiental, de educação em direitos humanos, de acessibilidade às pessoas com mobilidade reduzida, e das que tratam da equidade e diversidade de gênero, de orientação sexual, de pessoas com deficiência e de educação das relações étnicoraciais;

IV. Às bases referenciais psicológicas e humanísticas da relação profissional-paciente para o atendimento odontológico das diferentes faixas etárias;

V. À Educação em saúde e às novas tecnologias de informação e comunicação em Odontologia e linguagens oficiais adotadas no território brasileiro (Língua Portuguesa e Libras).

VI. Ao conhecimento e aplicação do método científico para a realização de projetos de pesquisa e análise crítica de artigos científicos, como fonte válida de referência para a tomada de decisão baseada em evidências científicas.

Nas Ciências Odontológicas, incluem-se os seguintes conteúdos teóricos e práticos: 
I. Da propedêutica clínica: acolhimento, coleta, interpretação e análise de informações sobre história clínica, exame físico, conhecimento fisiopatológico dos sinais e sintomas, exames complementares; bem como os métodos para o desenvolvimento do processo de diagnóstico;

II. Da clínica odontológica integrada, diagnóstico, prognóstico, prevenção, e elaboração de projetos terapêuticos singulares e adoção de condutas terapêuticas singulares na abordagem de doenças e agravos que acometem a saúde bucal e o equilíbrio do sistema estomatognático do ser humano em todas as fases do ciclo de vida, considerando-se o perfil epidemiológico e as realidades locais;

III. Das técnicas e habilidades para a interceptação e o tratamento das doenças e agravos bucais, assim como para a restauração e reabilitação estético-funcional e a manutenção do equilíbrio do sistema estomatognático e da saúde bucal, relações com as condições sistêmicas e a integralidade do indivíduo nas diferentes fases do ciclo de vida, e se baseando em evidências científicas e incorporação de inovações tecnológicas no exercício da profissão na perspectiva interprofissional;

IV. Da prescrição clínica racional da terapêutica medicamentosa em Odontologia, e do uso de técnicas anestésicas locais e regionais, de maneira a proporcionar terapêuticas eficazes e seguras aos indivíduos atendidos;

V. Da abordagem de emergência e do suporte básico de vida no caso de acidentes que comprometam a vida e a saúde do indivíduo;

VI. Da composição e das propriedades químicas, físicas e biológicas dos materiais empregados em Odontologia, assim como das técnicas de manipulação e seleção de acordo com suas indicações clínicas com base em evidências científicas;

VII. Do manuseio de aparelhos de radiação-X alicerçados nos princípios da radioproteção, das técnicas para a tomada e revelação de radiografias intraorais, assim como interpretação de imagens dos diferentes métodos de diagnósticos por imagens em Odontologia;

VIII. Dos princípios de biossegurança e ergonomia na prática odontológica, de acordo com as normas legais e regulamentares pertinentes;

IX. Dos conceitos de perícias odontológicas e auditoriais, assim como das exigências legais para instalação e funcionamento de um consultório odontológico;

X. Do atendimento clínico odontológico ambulatorial do indivíduo com necessidades especiais;

XI. Da assistência odontológica a indivíduos institucionalizados ou internados em ambiente hospitalar;

XII. Da gestão e planejamento organizacional e profissional dos serviços de saúde, assim como das atribuições dos técnicos de saúde bucal, auxiliar de saúde bucal, técnico em prótese dentária e auxiliar de prótese dentária.

Os conteúdos curriculares devem contemplar os conteúdos pertinentes às políticas de educação ambiental, de educação em direitos humanos e de educação das relações étnico-raciais e para o ensino de história e cultura afro-brasileira, africana e indígena. Complementarmente, o PDI e o PPC devem contemplar a descrição de políticas de direitos humanos, desenvolvidas no curso, que tratam da equidade e diversidade de gênero e do combate à violência contra a mulher. 


\begin{tabular}{|c|c|}
\hline $\begin{array}{l}\text { DOCUMENTOS NECESSÁRIOS: } \\
\text { PDI; } \\
\text { PPC; } \\
\text { DCN dos cursos de graduação em Odontologia; } \\
\text { Resolução CNE/CES n. 02/20079 e Resolução } \\
\text { CNE/CES n. 04/2009; } \\
\text { Glossário dos Instrumentos de Avaliação externa do } \\
\text { INEP - 2018; } \\
\text { Planos de Ensino; } \\
\text { Planos de Aula. }\end{array}$ & 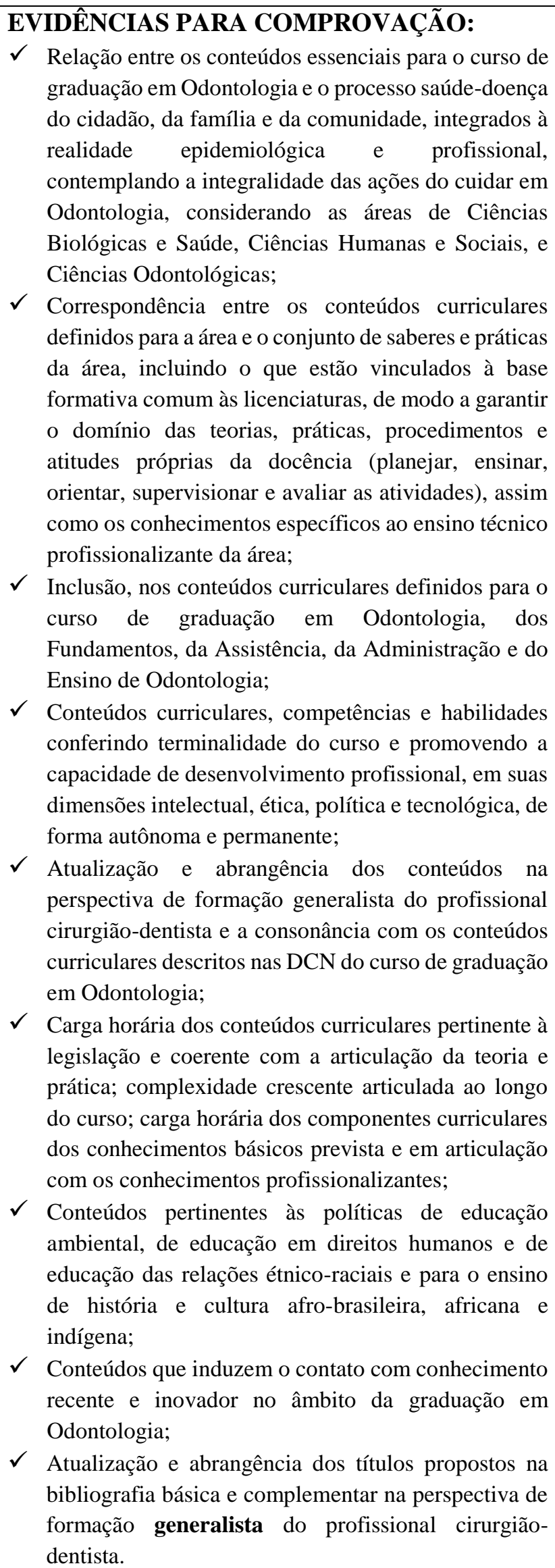 \\
\hline
\end{tabular}




\section{Metodologia}

O curso de graduação em Odontologia deve se caracterizar pela existência de metodologias de ensino/aprendizagem, descritas nos planos de ensino, que permitam a participação ativa do estudante e a integração dos conhecimentos básicos com os clínicos, além da existência de programas de iniciação científica e de extensão como método de aprendizagem. Para o desenvolvimento de um projeto pedagógico com características metodológicas que o diferenciem como sendo centrado no aprendizado do estudante, é necessário observar programas e iniciativas institucionais de capacitação dos docentes para utilização de metodologias inovadoras de ensino-aprendizagem, e políticas institucionais de incentivo à adoção destas metodologias.

Em relação à acessibilidade plena, a metodologia deve estar consoante com as estratégias e atividades educacionais relacionadas ao ensino, em especial a ausência de barreiras pedagógicas, atitudinais, digitais e nas comunicações. A concepção subjacente à atuação docente quanto ao conhecimento, à aprendizagem, à avaliação e à inclusão educacional dos estudantes público alvo da educação especial na educação superior influencia a metodologia de ensino proposta pelo curso. Destaca-se, ainda, a necessária eliminação de barreiras na comunicação interpessoal (face a face, língua de sinais, tadoma), escrita (jornal, revista, livro, carta, apostila; incluindo textos em Braille, grafia ampliada, uso do computador portátil, site institucional em linguagem acessível em todos os módulos) e virtual (acessibilidade digital).

A acessibilidade plena implica, ainda, o direito de eliminação de barreiras na disponibilidade de comunicação, de acesso físico, de tecnologias assistivas (recursos que contribuem para proporcionar habilidades funcionais de pessoas com deficiência, promovendo independência e inclusão) compreendendo equipamentos e programas adequados, de conteúdo e apresentação da informação em formatos alternativos. A concepção de metodologia de ensino, nessa perspectiva, pode ser desenvolvida com o auxílio de uma equipe multidisciplinar atuante no Núcleo de Acessibilidade ou equivalente, assim como do Núcleo de Apoio Pedagógico e Experiência Docente.

A coerência das metodologias com o perfil profissional do egresso, com a estrutura curricular e com os conteúdos curriculares é almejada, de modo a evidenciar a adequação da metodologia à concepção do curso.

\begin{tabular}{|c|c|}
\hline $\begin{array}{l}\text { DOCUMENTOS NECESSÁRIOS: } \\
\checkmark \text { PPC; } \\
\checkmark \text { DCN dos cursos de graduação em Odontologia; } \\
\checkmark \text { Projetos e iniciativas do curso; } \\
\checkmark \text { Políticas institucionais de incentivo à adoção de } \\
\quad \text { metodologias ativas e inovadoras do ensino- } \\
\quad \text { aprendizagem; } \\
\checkmark \text { Relatórios de atividades desenvolvidas; } \\
\checkmark\end{array}$ & $\begin{array}{l}\text { EVIDÊNCIAS PARA COMPROVAÇÃO: } \\
\checkmark \text { Implantação de metodologias de ensino/aprendizagem } \\
\text { descritas nos planos de ensino que permitam a participação } \\
\text { ativa dos alunos, além de programas e iniciativas } \\
\text { institucionais de capacitação dos docentes para utilização } \\
\text { destas metodologias; } \\
\checkmark \text { Implantação de programas/projetos de iniciação científica, } \\
\text { de extensão e outros, como princípio educativo; } \\
\checkmark \text { Implantação de práticas de aprendizagem orientadas pela } \\
\text { aceitação ativa das diversidades sociais e humanas de } \\
\text { gênero, raça, etnia, classe social, geração, orientação sexual } \\
\text { e necessidades especiais (deficiências, patologias, } \\
\text { transtornos etc.); } \\
\checkmark \text { Implantação de estratégias diferenciadas e inovadoras nas } \\
\text { aulas e atividades acadêmicas, embasada em recursos que } \\
\text { proporcionam aprendizagens diferenciadas na área de } \\
\text { Odontologia. }\end{array}$ \\
\hline
\end{tabular}




\section{Estágio curricular supervisionado}

O estágio curricular supervisionado em IES é compreendido, segundo a Lei n. 11.788/2008, em seu Art. $1^{\circ}, \S 2^{\circ}$, como "ato educativo escolar supervisionado, desenvolvido no ambiente de trabalho, que visa à preparação para o trabalho produtivo (...) [e] ao aprendizado de competências próprias da atividade profissional e à contextualização curricular, objetivando o desenvolvimento do educando para a vida cidadã e para o trabalho".

A formação do cirurgião-dentista deve garantir o desenvolvimento de estágios curriculares desenvolvidos de forma articulada com o SUS e com complexidade crescente ao longo do processo de formação para atender as DCN dos cursos de graduação em Odontologia.

O SUS é o efetivo ordenador da formação de recursos humanos na área da Saúde e a articulação da área da educação com a área da saúde deve contribuir para a real transformação dos serviços públicos em campos essenciais de estágio curricular supervisionado.

A articulação com o SUS deve ser regulada por meio de instrumento legal pertinente como contratos organizativos, convênios, celebrados entre as Instituições de saúde e a IES, trabalhando na perspectiva de parceria interinstitucional. A integração ensino-serviço vivenciada nas atividades de promoção, prevenção de agravos, reabilitação da saúde deve enfatizar o processo de trabalho em equipe interprofissional e interdisciplinar, atendendo ao princípio da integralidade de atenção à saúde.

O estágio deve se desenvolver com capacitação de preceptores do campo de estágio e de professores da IES, baseado na ciência e na realidade dos serviços. Também deve estimular a formulação de referencial epidemiológico em saúde bucal na região da IES, possibilitando o estabelecimento de metas comuns para o serviço de saúde e para o curso de graduação em Odontologia. Assim como estabelecer o fluxo de referência e contra referência sistematizado e valorizado por ambas as partes.

Entende-se por ato educativo supervisionado o desenvolvimento de atividades que aperfeiçoem o aprendizado do aluno sob a responsabilidade de professor cirurgião-dentista da IES, que desempenhe a coordenação e a supervisão direta e desenvolva sua capacidade de proporcionar a construção do conhecimento, em especial pelo estímulo a práticas de estudo independente, visando uma progressiva autonomia intelectual e profissional do aluno; desenvolvido obrigatoriamente no ambiente real de trabalho, que visa à formação social, humana e científica do aluno, preparando-o para o trabalho profissional da Odontologia na sociedade.

Ambiente de trabalho é o local no qual são desenvolvidas atividades relacionadas diretamente às competências gerais e específicas de um cirurgião-dentista. Este ambiente é configurado por serviços de saúde inseridos no mundo do trabalho, providos de profissionais de saúde que compõem o quadro de pessoal, realizando atividades com grupo de indivíduos (ações coletivas), com pacientes (assistência individual) e de gestão. A atenção integral à saúde bucal na perspectiva do cirurgião-dentista generalista deve ser o balizador do "ambiente de trabalho" não sendo admissível, do ponto de vista da formação em Odontologia, considerar a fragmentação das necessidades de saúde das pessoas.

A flexibilização dos cenários intramurais e extramurais à IES, desde que articulados ao SUS, permitirá que cada curso discuta suas opções e as coloquem em prática de acordo com o Projeto 
Pedagógico do Curso (PPC) e a obtenção do perfil do egresso almejado, em consonância com as DCN.

As clínicas odontológicas intramurais, ambulatórios, hospitais e outros espaços de desenvolvimento de atividades de promoção de saúde, prevenção de doença, assistência e recuperação da saúde próprios das IES são cenários do estágio somente se configurados como serviço público de saúde integrado ao SUS, comprovado por meio de instrumento legal pertinente, agenda integrada, sistema de regulação de pacientes, viabilizando o estabelecimento de fluxo de referência e contra referência.

O estágio intra e extramural nas clínicas integradas de atenção básica com complexidade crescente, onde os alunos desenvolvem competências realizando atividades de educação e promoção de saúde até à reversão do dano são considerados cenários de estágio curricular supervisionado do curso de graduação em Odontologia, desde que o estudante realize a atenção básica resolutiva, contemplando o atendimento integral ao paciente.

O estágio deve permitir que a experiência profissional desenvolvida ao longo de suas atividades possibilite ao estudante o reconhecimento da realidade social, do funcionamento dos serviços de saúde, articule a teoria com a prática em situação real e cotidiana, conheça a realidade do mundo de trabalho e se aproprie dos pressupostos teórico-metodológicos do sistema de saúde, em todas as suas dimensões. Fomentar a integração ensino-serviço-comunidade e ampliar as relações da IES com a sociedade, colocando o futuro profissional em contato com as diversas realidades sociais (locais, regionais e nacionais), incluindo as práticas e políticas em saúde coletiva devem ser os grandes objetivos do estágio curricular.

A carga horária do estágio curricular deve corresponder a $20 \%$ da carga horária total do Curso e não substitui a carga horária em atividades práticas que envolvem o atendimento de pacientes, exigida para o desenvolvimento das competências e habilidades clínicas específicas de cada disciplina. As clínicas isoladas de uma ou mais disciplinas e as aulas práticas laboratoriais não são consideradas para efeito de estágio supervisionado.

O cumprimento de $100 \%$ da carga horária total dos estágios nos diversos espaços do SUS como cenários de aprendizagem é considerado a condição ideal desejável.

Como condição mínima suficiente $50 \%$ da carga horária total do estágio curricular é desenvolvida fora das clínicas da IES, sendo a metade desta carga horária extramural desenvolvida obrigatoriamente no SUS.

Para o estágio curricular é obrigatório o acompanhamento e orientação efetivos presenciais in loco por um docente do curso de graduação em Odontologia da própria IES, sendo a relação entre o número de estudantes e docentes, no mínimo um docente para 12 (doze) alunos. A supervisão e coordenação do estágio devem estar previstas no regulamento do estágio supervisionado do curso de graduação em Odontologia.

Deve-se buscar o envolvimento de professores de diferentes campos de conhecimento aproximando a saúde coletiva da clínica odontológica, por meio do trabalho conjunto na supervisão de estágios curriculares. 


\begin{tabular}{|c|c|}
\hline $\begin{array}{ll} & \text { DCN dos cursos de graduação em } \\
& \text { Odontologia; } \\
\checkmark & \text { PPC; } \\
\checkmark & \text { Lei no } 11.788 \text {, de } 25 \text { de setembro de 2008; } \\
\checkmark & \text { Resolução 350/CNS/2005; } \\
\checkmark & \text { Termos dos convênios entre as IES e as } \\
& \text { instituições públicas de saúde firmados pela } \\
& \text { IES, comparando-os com o previsto na lei, } \\
& \text { assim como toda documentação que visa à } \\
& \text { garantia dos direitos dos estagiários; ; } \\
\checkmark & \text { Termo de compromisso com o educando e a } \\
& \text { instituição de saúde; } \\
\checkmark & \text { Relatório de atividades do educando em } \\
& \text { relação ao campo de estágio; } \\
\checkmark & \text { Relação das instalações dos locais de } \\
& \text { estágio; } \\
\checkmark & \text { Relatórios de avaliação do aluno (IES/ } \\
& \text { Instituição de saúde); } \\
\checkmark & \text { Política de supervisão do preceptor; } \\
\checkmark & \text { Política de Educação permanente; } \\
\checkmark & \text { Regulamento do estágio para Curso de } \\
& \text { Graduação em Odontologia da IES. }\end{array}$ & $\begin{array}{l}\text { EVIDÊNCIAS PARA COMPROVAÇÃO: } \\
\checkmark \text { Adequação das normas de estágio específicas do } \\
\text { curso em conformidade com as DCN do Curso } \\
\text { de Graduação em Odontologia; } \\
\checkmark \text { Adequação dos campos e condições dos } \\
\text { espaços/locais utilizados para estágio curricular } \\
\text { supervisionado, permitindo que o estudante seja } \\
\text { efetivamente preparado para a abrangência da } \\
\text { atuação profissional e consonância com o SUS; } \\
\checkmark \text { Coerência das atividades previstas no estágio } \\
\text { curricular supervisionado e a complexidade } \\
\text { dessas para a constituição do perfil profissional; } \\
\checkmark \text { Maneira como as instituições de saúde fomentam } \\
\text { a relação ensino-serviço e ampliam as relações } \\
\text { da IES com a sociedade, assim como se } \\
\text { constituem em oportunidades de inserção do } \\
\text { futuro profissional nas diversas realidades } \\
\text { sociais (locais, regionais, nacionais e } \\
\text { internacionais); } \\
\checkmark \text { Formação técnico-profissional em Odontologia } \\
\text { dos preceptores de estágio, no âmbito das IES e } \\
\text { instituições de saúde; } \\
\checkmark \text { Relação de supervisão docente obedecendo a um } \\
\text { parâmetro de no mínimo 1 docente para cada } 12 \\
\text { alunos; } \\
\checkmark \text { Percentual de carga horária de estágio curricular } \\
\text { supervisionado desenvolvida no SUS fora dos } \\
\text { muros da IES; } \\
\text { Envolvimento de professores de diferentes áreas } \\
\text { na supervisão do estágio supervisionado; } \\
\text { Caracterização da IES como ponto da rede de } \\
\text { atenção à saúde do SUS ou como ponto de } \\
\text { referência dos profissionais do SUS; } \\
\text { Interlocução institucionalizada da IES com o(s) } \\
\text { ambiente(s) de estágio, gerando insumos para } \\
\text { atualização das práticas do estágio. }\end{array}$ \\
\hline
\end{tabular}

\section{Atividades complementares}

Para o Curso de Graduação em Odontologia importa considerar a instituição das atividades complementares como parte integrante do currículo pleno do curso conforme instituído pelas DCN dos cursos de graduação em Odontologia e considerando a importância da flexibilização curricular. 
Assim, o Curso de Graduação em Odontologia deve facultar ao estudante o desenvolvimento de programas complementares de estudos que fortaleçam a integração entre a teoria e a prática e lhe permita incorporar experiências que concorram para o seu crescimento profissional, "de forma a considerar a inserção institucional do curso, a flexibilidade individual de estudos e os requerimentos, demandas e expectativas de desenvolvimento do setor saúde na região" (DCN dos cursos de graduação em Odontologia).

As atividades complementares devem caracterizar-se pela diversidade, buscando-se mecanismos de aproveitamento de conhecimentos adquiridos pelo estudante, por meio de estudos e práticas independentes, a saber: monitorias e estágios não obrigatórios; programas/projetos de iniciação científica; programas/projetos de extensão; estudos complementares e cursos realizados em qualquer área do conhecimento, participação e/ou organização de eventos, participação em atividades do movimento estudantil, atividades culturais e desportivas, entre outras.

As atividades complementares devem possuir formas de aproveitamento, por meio de um regulamento institucionalizado e conhecido do corpo docente e discente e devem ser diferenciadas do estágio supervisionado obrigatório.

As ações desenvolvidas como atividades complementares, com carga horária prevista no PPC, devem contribuir com a área de formação e atuação profissional em Odontologia.

\section{DOCUMENTOS NECESSÁRIOS:}

$\checkmark$ PPC;

$\checkmark$ DCN dos cursos de graduação em Odontologia;

$\checkmark$ Regulamento das Atividades Complementares;

$\checkmark$ Registro de atividades desenvolvidas.

\section{EVIDÊNCIAS PARA COMPROVAÇÃO:}

$\checkmark$ Institucionalização do regulamento das atividades complementares, sendo conhecido pelos corpos docente e discente;

$\checkmark$ Definição de carga horária para as atividades complementares na estrutura curricular, segundo o PPC;

$\checkmark$ Abrangência e diversidade das atividades complementares desenvolvidas e formas de aproveitamento aderentes à formação geral e específica do discente;

$\checkmark$ Implantação de mecanismos comprovadamente exitosos ou inovadores na regulação, gestão e aproveitamento das atividades complementares.

\section{Trabalho de Conclusão de Curso (TCC)}

Para conclusão do Curso de Graduação em Odontologia, o aluno deverá elaborar um trabalho sob orientação docente (DCN dos cursos de graduação em Odontologia). O TCC constitui-se uma atividade acadêmica embasada cientificamente e suas temáticas devem apresentar coerência com o perfil do egresso.

As normas de elaboração do TCC devem ser definidas em regulamento institucionalizado e conhecido pelo corpo docente e discente. 
Quanto às formas de apresentação, devem constar no PPC constituindo-se numa oportunidade de experiência com a pesquisa/iniciação científica. Importa a existência de uma coordenação do TCC para o curso.

\section{DOCUMENTOS NECESSÁRIOS: \\ $\checkmark$ PPC; \\ $\checkmark$ DCN dos cursos de graduação em Odontologia; \\ $\checkmark$ Regulamento e Manual do TCC do Curso de Graduação em Odontologia.}

\section{EVIDÊNCIAS PARA COMPROVAÇÃO:}

$\checkmark$ Implantação de regulamento institucionalizado do TCC, conhecido pelos corpos docente e discente;

$\checkmark$ Compatibilidade entre as formas de apresentação do TCC e aquelas descritas no PPC;

$\checkmark$ Previsão, na estrutura curricular definida no PPC, de carga horária para a realização do TCC;

$\checkmark$ Existência de coordenação e de orientação docente do TCC para o curso;

$\checkmark$ Coerência entre as temáticas, as formas de apresentação do TCC e o perfil do egresso.

$\checkmark$ Análise e aprovação no respectivo Comitê de Ética e Pesquisa quando o trabalho envolver pesquisa com seres humanos ou animais;

$\checkmark$ Orientação de docente do curso na IES;

$\checkmark$ Meios de divulgação dos TCC apresentados em repositórios institucionais próprios, acessíveis pela internet.

\section{Apoio ao discente}

O curso de graduação em Odontologia deve contemplar a existência e o funcionamento de uma política ou programa institucional consolidado de apoio ao discente, conhecido pelos corpos docente e discente.

A implantação do apoio ao discente inclui, ainda, os programas de apoio extraclasse e psicopedagógico na instituição, voltados ao atendimento às necessidades educacionais apresentadas pelo corpo discente, inclusive o público alvo da educação especial no âmbito da educação superior.

As atividades de nivelamento e extracurriculares não computadas como atividades complementares constituem-se como estratégia de apoio ao discente.

Por participação dos discentes em centros acadêmicos, entende-se também a sua atuação em diretórios acadêmicos, ligas acadêmicas e outros movimentos estudantis. No que diz respeito aos intercâmbios, entende-se todas as ações em prol da mobilidade acadêmica.

O apoio ao discente possibilita a remoção de todo o tipo de barreiras ao público-alvo da educação especial, garantindo condições de igualdade no acesso, na permanência e na conclusão dos estudos na educação superior. Tais condições são promovidas institucionalmente a partir da eliminação do conjunto de barreiras, a saber: arquitetônicas, pedagógicas, atitudinais, nas comunicações e digitais. 


\begin{tabular}{|c|c|}
\hline 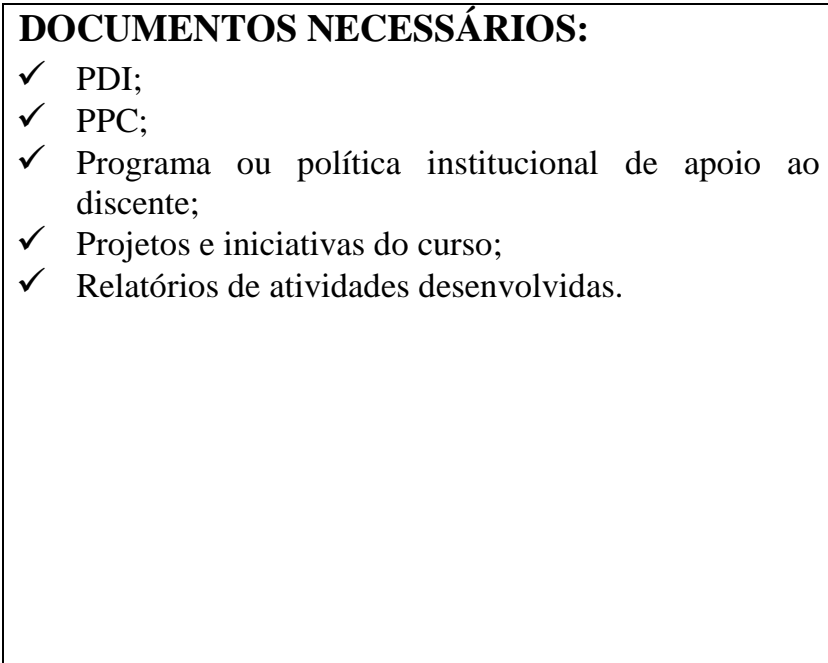 & $\begin{array}{l}\text { EVIDÊECIAS PARA COMPROVAÇÃO: } \\
\checkmark \quad \text { Funcionamento da política ou programa institucional } \\
\text { de apoio ao discente e que seja conhecido pelos } \\
\text { corpos docente e discente; } \\
\checkmark \quad \text { Funcionamento do programa de apoio extraclasse e } \\
\text { psicopedagógico na instituição; } \\
\checkmark \quad \begin{array}{l}\text { Existência e funcionamento de atividades de } \\
\text { nivelamento e extracurriculares não computadas }\end{array} \\
\text { como atividades complementares; } \\
\checkmark \text { Oferta de condições para existência e funcionamento } \\
\text { de centros, diretórios e ligas acadêmicas, entre outros } \\
\text { movimentos estudantis; } \\
\checkmark \quad \begin{array}{l}\text { Implantação do apoio à mobilidade acadêmica dos } \\
\text { estudantes ou intercâmbios nacionais e internacionais; }\end{array} \\
\checkmark \quad \begin{array}{l}\text { Ações comprovadamente exitosas e inovadoras no } \\
\text { apoio aos discentes. }\end{array}\end{array}$ \\
\hline
\end{tabular}

\section{Gestão do curso e os processos de avaliação interna e externa}

De acordo com as DCN dos cursos de graduação em Odontologia, "a implantação e desenvolvimento das diretrizes curriculares devem orientar e propiciar concepções curriculares ao curso de graduação em Odontologia que deverão ser acompanhadas e permanentemente avaliadas, a fim de permitir os ajustes que se fizerem necessários ao seu aperfeiçoamento".

Desta forma, é necessária a realização de auto avaliações, avaliações externas, Enade, entre outras. Os resultados das avaliações internas e externas possibilitam identificar os aspectos que dificultam e/ou facilitam a gestão acadêmica do curso, assim como sugerir estratégias de intervenção para corrigir rumos, consolidar sua ação pedagógica e alcançar efetivamente maior qualidade no ensino-aprendizagem. Portanto, as ações decorrentes dos processos de avaliação do curso devem ser evidenciadas em medidas de melhoria do curso.

Em relação às avaliações internas no âmbito do curso, a coordenação do curso de graduação em Odontologia deve realizar ações com vistas à auto avaliação do próprio curso complementando as ações da Comissão Própria de Avaliação (CPA).

\section{DOCUMENTOS NECESSÁRIOS:}

$\checkmark$ PDI;

$\checkmark$ PPC;

$\checkmark$ DCN dos cursos de graduação em Odontologia;

$\checkmark$ Programa de Avaliação Institucional por meio de ações realizadas pela CPA para o curso;

$\checkmark$ Projetos e iniciativas de auto avaliação do próprio curso;

$\checkmark$ Relatórios de resultados consolidados de auto avaliação da CPA e outras das respectivas ações desenvolvidas;

$\checkmark \quad$ Atas de reuniões do Núcleo Docente Estruturante NDE, Colegiado, entre outros.

\section{EVIDÊNCIAS PARA COMPROVAÇÃO:}

$\checkmark$ Utilização dos dados das avaliações internas e externas para análise crítica dos resultados e das atividades desenvolvidas pelo curso que servirão de base para o planejamento estratégico do mesmo, por meio das atas do Núcleo Docente Estruturante NDE, Colegiado, entre outros;

$\checkmark$ Estratégias de intervenção para corrigir rumos, consolidar a ação pedagógica e alcançar efetivamente maior qualidade no ensino-aprendizagem com base nos resultados das autoavaliações, avaliações internas e externas do curso;

$\checkmark$ Relação entre a CPA e a gestão do curso;

$\checkmark$ Participação dos discentes e docentes nos processos de avaliação e etapas subsequentes, com evidências de apropriação dos resultados pela comunidade acadêmica;

$\checkmark$ Periodicidade do processo de autoavaliação do curso de graduação em Odontologia. 


\section{Atividades de tutoria}

Quando o curso de graduação em Odontologia opta por oferecer até $20 \%$ de sua $\mathrm{CH}$ total na modalidade à distância deve contemplar a Resolução CFO 186/2017. As atividades de tutoria devem estar expressas no PPC na parte de metodologia. A tutoria deve ser passível de verificação nos planos de ensino, do conhecimento dos discentes e docentes e atender às demandas didático-pedagógicas da estrutura curricular proposta (ver Glossário dos Instrumentos de Avaliação Externa do INEP - 2018 para a definição de tutoria).

As atividades de tutoria são realizadas pelos professores como suporte ao processo de ensinoaprendizagem. Podem envolver ações diretas e indiretas, de comunicação síncrona (ambos os atores conectados ao mesmo tempo) ou assíncrona (atores se comunicam em tempos distintos). Podem incluir desenvolvimento de tarefas por parte dos alunos, sempre sob supervisão do tutor designado.

Para o desenvolvimento de um bom trabalho de tutoria, este não pode envolver mais do que 12 alunos por professor.

De acordo com a Portaria MEC nº 4.059, de 10 de dezembro de 2004 (DOU de 13/12/2004, Seção 1, p. 34), artigo $2^{\circ}$ : “A oferta das disciplinas previstas no artigo anterior deverá incluir métodos e práticas de ensino-aprendizagem que incorporem o uso integrado de tecnologias de informação e comunicação para a realização dos objetivos pedagógicos, bem como prever encontros presenciais e atividades de tutoria."

\begin{tabular}{|c|c|}
\hline $\begin{array}{ll}\text { DOCUMENTOS NECESSÁRIOS: } \\
\checkmark & \text { PDI; } \\
\checkmark & \text { PPC; } \\
\checkmark & \text { Planos de Ensino e registros das atividades de } \\
& \text { tutoria; } \\
\checkmark & \text { Registros nos Ambientes Virtuais utilizados; } \\
\checkmark & \text { Registro dos encontros presenciais; } \\
\checkmark & \text { Resultados da avaliação dos alunos acerca das } \\
& \text { atividades de tutoria; } \\
\checkmark & \text { Planejamento de ações de melhorias das } \\
& \text { atividades de tutoria do Curso de Graduação em } \\
& \text { Odontologia. }\end{array}$ & 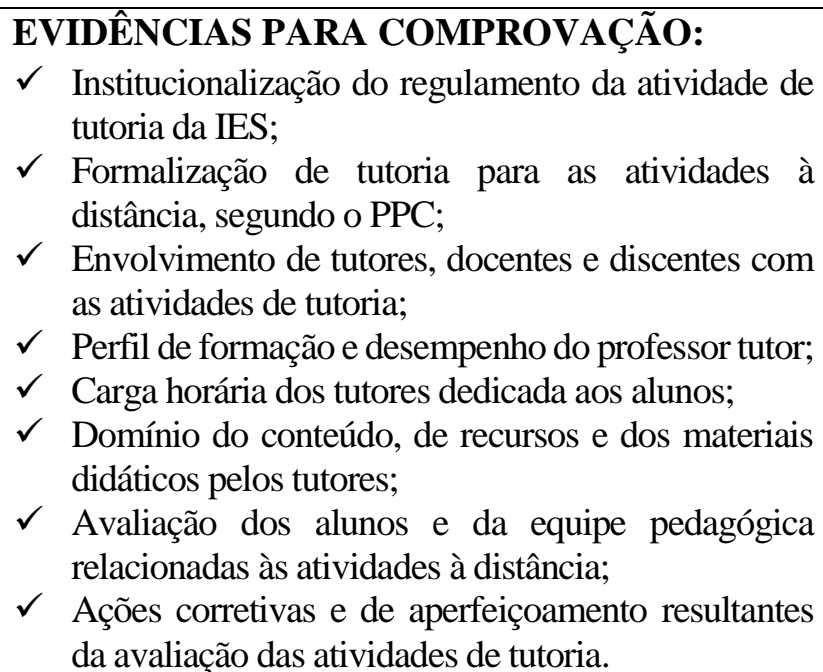 \\
\hline
\end{tabular}

\section{Tecnologias de Informação e Comunicação (TIC) no processo ensino/aprendizagem}

Conforme Glossário dos Instrumentos de Avaliação Externa do INEP - 2018, as TIC "são recursos didáticos constituídos por diferentes mídias e tecnologias, síncronas e assíncronas, tais como ambientes virtuais e suas ferramentas, redes sociais e suas ferramentas, fóruns eletrônicos, blogs, chats, tecnologias de telefonia, teleconferências, videoconferências, TV, rádio, programas específicos de computadores (softwares), objetos de aprendizagem, conteúdos disponibilizados em suportes tradicionais (livros) ou em suportes eletrônicos".

O curso de graduação em Odontologia, mesmo não utilizando $20 \%$ de sua carga horária total na modalidade a distância ou semipresencial, deve utilizar as TIC que contribuam para a execução do seu projeto pedagógico. Estas tecnologias devem permear todo o desenvolvimento do curso, não caracterizando atividades pontuais. Seu emprego deve ser do domínio dos docentes e discentes. 
A garantia de acessibilidade plena ao público alvo da educação especial, que implica promover condições de igualdade no acesso, na permanência e na conclusão dos estudos na educação superior, tem relação com a eliminação de barreiras na disponibilidade de comunicação, de acesso físico, de tecnologias assistivas (recursos que contribuem para proporcionar habilidades funcionais de pessoas com deficiência, promovendo independência e inclusão) compreendendo equipamentos e programas adequados, de conteúdo e apresentação da informação em formatos alternativos.

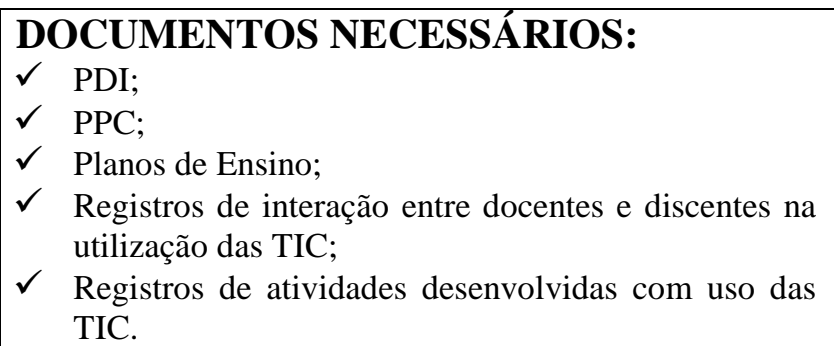

\section{EVIDÊNCIAS PARA COMPROVAÇÃO:}

$\checkmark$ Utilização de TIC no curso de graduação em Odontologia;

$\checkmark$ Formas de interação entre docentes e discentes na utilização das TIC;

$\checkmark$ Ações de nivelamento para promoção de acessibilidade digital e comunicacional;

$\checkmark$ Experiências diferenciadas de aprendizagem baseadas em seu uso.

\section{Ambiente Virtual de Aprendizagem - AVA e Material didático}

Quando o curso de graduação em Odontologia opta por oferecer até 20\% de sua carga horária total na modalidade a distância ou semipresencial, deve disponibilizar aos estudantes um Ambiente Virtual de Aprendizagem e Material Didático. O Material Didático é entendido como componente essencial da qualidade da comunicação entre a instituição e o aluno, tais como guias, tutoriais e manuais do aluno. Permite executar a formação definida no Projeto Pedagógico do Curso, considerando os conteúdos específicos, objetivos, técnicas e métodos.

O material didático pode incluir os mais diversos tipos, desde que adequados à mídia em utilização: slides para aula presencial não são eficazes na comunicação mediada por tecnologia (devem ser acompanhados de explicações textuais ou de áudio).

Podem ser utilizados os mais diversos formatos (apostilas eletrônicas, e-Books, planilhas, infográficos, imagens, podcasts, vídeos, etc.). Os Objetos de Aprendizagem são uma instância à parte por incluírem a avaliação do conteúdo abordado.

Há uma tendência mundial para a produção de Recursos Educacionais Abertos (REA) e tais atividades podem ser consideradas de inserção social pela produção de conhecimento aberto de acesso facilitado às populações.

\begin{tabular}{|c|c|}
\hline 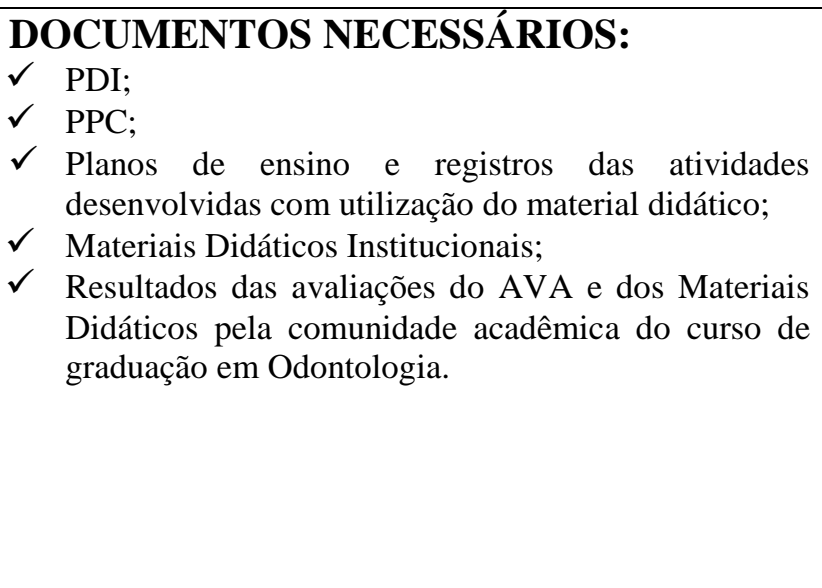 & $\begin{array}{ll}\text { EVIDÊNCIAS PARA COMPROVAÇÃO: } \\
\checkmark \text { Existência e qualidade do material didático; } \\
\checkmark \text { Validação do Material Didático pelo NDE do curso de } \\
\text { graduação em Odontologia; } \\
\checkmark \text { Adequação da bibliografia, abrangência, aprofundamento, } \\
\text { coerênia teórica, acessibilidade metodológica e } \\
\text { instrumental, linguagem inclusiva e acessível do Material } \\
\checkmark \text { Didático do curso de graduação em Odontologia; } \\
\checkmark \text { Operabilidade do AVA; } \\
\checkmark \text { Avaliação do AVA por docentes, discentes e tutores; } \\
\checkmark \quad \text { Ações de melhorias do AVA e do Material Didático do } \\
\quad \text { curso de graduação em Odontologia resultantes das } \\
\checkmark \text { avaliações da comunidade acadêmica; } \\
\checkmark \text { Recursos comprovadamente inovadores. }\end{array}$ \\
\hline
\end{tabular}




\section{Procedimentos de acompanhamento e de avaliação dos processos de ensino-aprendizagem}

As avaliações dos alunos devem ser coerentes com as competências, habilidades e conteúdos curriculares desenvolvidos, tendo como referência as DCN dos cursos de graduação em Odontologia, assim como devem atender à concepção de avaliação definida no PPC. Considerando o caráter processual de desenvolvimento de competências e habilidades do perfil profissional, os processos de avaliação devem possuir caráter diagnóstico, formativo e processual, buscando o equilíbrio entre os aspectos qualitativos e quantitativos.

O curso de graduação em Odontologia deverá utilizar metodologias e critérios para acompanhamento e avaliação do processo ensino-aprendizagem e do próprio curso, em consonância com o sistema de avaliação e a dinâmica curricular, definidos pela IES à qual pertence.

Em conformidade com a metodologia proposta no PPC, deve ser garantida a acessibilidade plena nas avaliações, assim como devem ser desenvolvidas por meio de métodos e instrumentos diversificados. Deve-se garantir a adequação dos instrumentos de avaliação conforme a natureza das atividades (teórica, prática e de estágio curricular supervisionado).

No curso de graduação em Odontologia, as avaliações devem ser desenvolvidas por meio de métodos e instrumentos diversificados consonantes com as metodologias de ensino adotadas nos Planos de Ensino; importa a existência de instrumentos de operacionalização de avaliações para os componentes curriculares com teor prático e a adequação dos instrumentos utilizados às atividades desenvolvidas na carga horária prática correspondente.

Para as atividades práticas do curso de graduação em Odontologia é essencial a obediência à proporção de docentes por alunos: nos estágios supervisionados no mínimo um docente para 12 (doze) alunos e nas atividades práticas laboratoriais dos conteúdos pré-profissionalizantes no mínimo um docente para 15 (quinze) alunos.

Para a supervisão à assistência odontológica, nos componentes curriculares que envolvem atividades/aulas/procedimentos odontológicos em clínicas de ensino, é necessário considerar os seguintes critérios de relação aluno/docente:

- Não atende: um docente para oito unidades de atendimento, constituída no máximo com dois alunos trabalhando a quatro mãos.

- Insuficiente: um docente para sete unidades de atendimento, constituída no máximo com dois alunos trabalhando a quatro mãos.

- Suficiente: um docente para seis unidades de atendimento, constituída no máximo com dois alunos trabalhando a quatro mãos.

- Muito bom: um docente para cinco unidades de atendimento, constituída no máximo com dois alunos trabalhando a quatro mãos.

- Excelente: um docente para quatro unidades de atendimento, constituída no máximo com dois alunos trabalhando a quatro mãos. 


\begin{tabular}{|c|c|}
\hline $\begin{array}{l}\text { DOCUMENTOS NECESSÁRIOS: } \\
\checkmark \text { PPC; } \\
\checkmark \text { DCN dos cursos de graduação em Odontologia; } \\
\checkmark \text { Projetos do curso do curso de graduação em } \\
\text { Odontologia; } \\
\checkmark \text { Instrumentos de avaliação do curso de graduação } \\
\text { em Odontologia; } \\
\checkmark \quad \text { Provas e testes, caso sejam utilizados do curso de } \\
\text { graduação em Odontologia; } \\
\checkmark \text { Relatórios de avaliação prática; } \\
\checkmark \text { Instrumentos aplicados para avaliação do } \\
\text { processo de ensino-aprendizagem em } \\
\text { consonância com as competências, habilidades e } \\
\text { conteúdos curriculares definidos no PPC. }\end{array}$ & 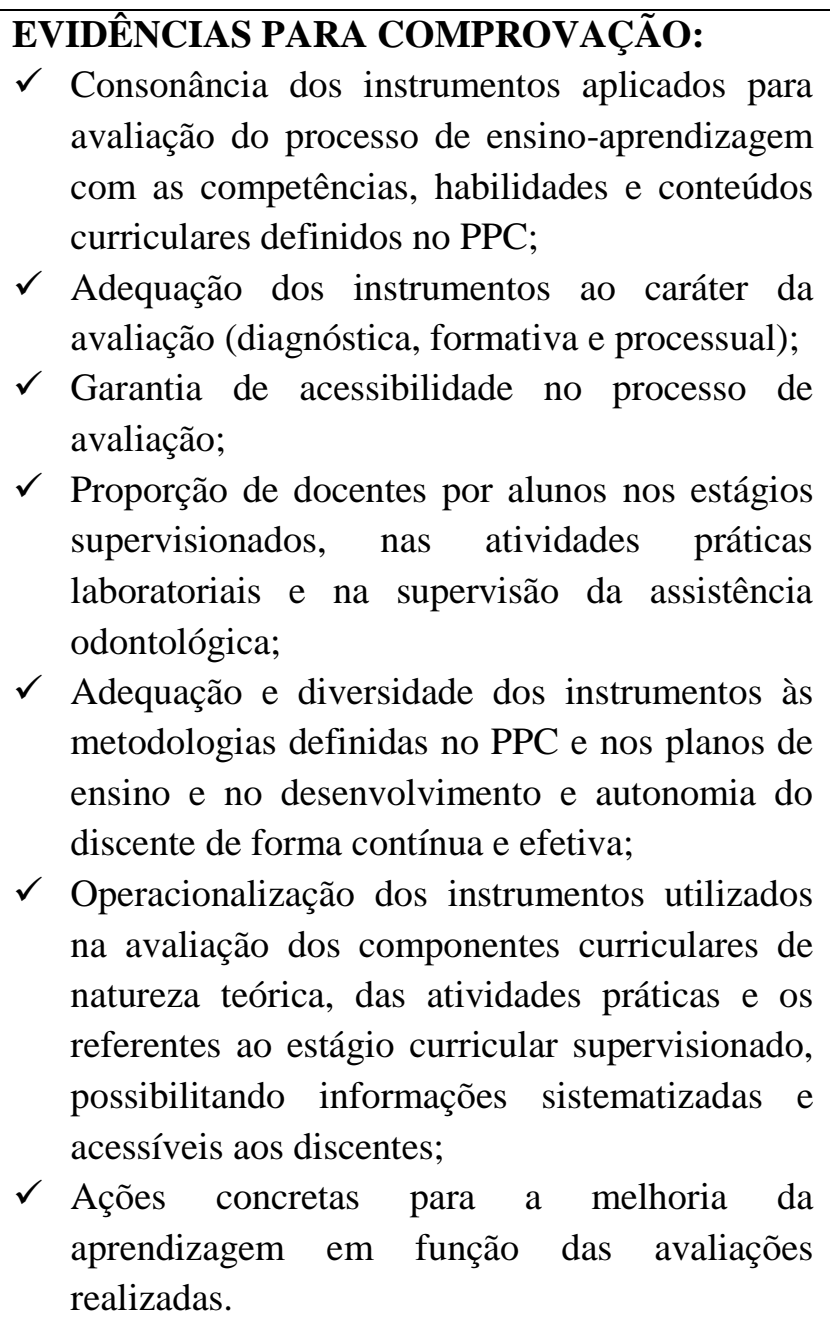 \\
\hline
\end{tabular}

\section{Número de vagas}

O número de vagas deve ser coerente com a capacidade do curso (corpo docente e condições de infraestrutura), às exigências do meio e estar claramente previsto no cronograma de implantação e desenvolvimento da instituição. Vale ressaltar que a capacidade do curso diz respeito também à absorção de novos estudantes e à oferta de campo para as atividades práticas e de estágio curricular supervisionado.

Para as atividades práticas do curso de graduação em Odontologia é essencial a obediência à proporção de docentes por alunos, considerando a relação aluno/docente mínima:

1. Nos estágios supervisionados, um docente para 12 (doze) alunos;

2. Nas atividades práticas laboratoriais, dos conteúdos pré-profissionalizantes, um docente para 15 (quinze) alunos;

3. $\mathrm{Na}$ supervisão à assistência odontológica, nos componentes curriculares que envolvem atividades/aulas/procedimentos odontológicos em clínicas de ensino, é necessário considerar os seguintes critérios de relação alunos/docente:

- Não atende: um docente para oito unidades de atendimento, constituída no máximo com dois alunos trabalhando a quatro mãos.

- Insuficiente: um docente para sete unidades de atendimento, constituída no máximo com dois alunos trabalhando a quatro mãos. 
- Suficiente: um docente para seis unidades de atendimento, constituída no máximo com dois alunos trabalhando a quatro mãos.

- Muito bom: um docente para cinco unidades de atendimento, constituída no máximo com dois alunos trabalhando a quatro mãos.

- Excelente: um docente para quatro unidades de atendimento, constituída no máximo com dois alunos trabalhando a quatro mãos.

Para definição do número de vagas é essencial descrever a realidade epidemiológica da população adstrita ao curso, assim como o número profissionais cirurgiões-dentistas e o número de IES que ofertam curso de graduação em Odontologia na região.

O contexto educacional dos cursos de graduação em Odontologia deve estar relacionado às questões de natureza social, científica, cultural e às reais necessidades de saúde no seu âmbito de atuação. Considerando as especificidades da área, deve ser sinalizada no contexto educacional a condição da fluoretação das águas de abastecimento público da região de influência do curso, as características epidemiológicas da saúde bucal dessa população, formas de organização da sociedade, vulnerabilidades, risco social, acesso/acessibilidade, equipamentos sociais, formas de controle social, a estrutura da rede de atenção em saúde (SUS) na região do curso e a cobertura das equipes de saúde bucal em relação à área de influência do curso (municípios e estado).

\section{DOCUMENTOS NECESSÁRIOS:}

$\checkmark$ DCN dos cursos de graduação em Odontologia;

$\checkmark$ Parecer CNE/CES 1.300, de 4 de dezembro de 2001;

$\checkmark$ PDI;

$\checkmark$ PPC;

$\checkmark$ Plano Municipal de Saúde;

$\checkmark$ Resolução 350/CNS/2005;

$\checkmark$ Levantamento epidemiológico das condições de saúde bucal loco regionais;

$\checkmark$ Relação dos cursos de graduação em Odontologia públicos e privados com os respectivos números de vagas anuais do município e municípios circunvizinhos;

$\checkmark \quad$ Número de cirurgiões-dentistas do município e municípios circunvizinhos.

\section{EVIDÊNCIAS PARA COMPROVAÇÃO:}

$\checkmark$ Relação entre o número de vagas ofertadas e a composição do quadro de corpo docente do curso;

$\checkmark$ Proporção de docentes por alunos nos estágios supervisionados, nas atividades práticas laboratoriais e na supervisão da assistência odontológica;

$\checkmark$ Relação entre o número de vagas e as condições de infraestrutura física e tecnológica do curso, em especial salas de aula; laboratórios didáticos especializados; espaços/áreas para atividades práticas e estágio curricular supervisionado;

$\checkmark$ Relação entre o número de vagas ofertadas pelo curso e demais vagas ofertadas por IES do município e municípios circunvizinhos;

$\checkmark$ Situação epidemiológica das condições de saúde bucal loco regionais;

$\checkmark$ Situação do serviço público de saúde, permitindo condição adequada no desenvolvimento de atividades educativas e integração ensino-serviço, compatível com o total de vagas previstas para o curso.

$\checkmark$ Contribuição do curso para a superação dos desequilíbrios na oferta de profissionais de saúde existentes considerando a relação entre a distribuição das ofertas de formação e a distribuição da população e a atual disponibilidade e distribuição de profissionais. 


\section{Integração do curso com o sistema local e regional de saúde/SUS}

A formação do cirurgião-dentista deverá incluir, como etapa integrante da graduação, o SUS, compreendendo-o como cenário de atuação profissional e campo de aprendizado que articula ações e serviços para a formação profissional. Deverá contemplar a atenção integral à saúde em um sistema regionalizado e hierarquizado de referência e contra referência, e o trabalho em equipe interprofissional.

A integração do curso com o sistema local e regional de saúde/SUS avalia um elemento de consolidação da formação do egresso em Odontologia, devendo constar na estrutura do curso a descrição da previsão/existência de ações de integração com o sistema local, regional e nacional de saúde no contexto do SUS para os cursos de graduação em Odontologia.

A integração do curso com o sistema local e regional de saúde/SUS deve aferir a relação aluno/docente/preceptor nos cenários de prática, atendendo aos princípios éticos da formação e atuação profissional.

A integração se evidencia pela existência de convênios e/ou contratos organizativos (por exemplo, os Contratos Organizativos de Ação Pública Ensino-Saúde - COAPES) e de outros documentos que demonstram a articulação do curso com os serviços de saúde, bem como dos mecanismos que asseguram a inserção dos alunos nas atividades do sistema de saúde, o acompanhamento dessas atividades e a relação com os usuários, em diferentes etapas da formação.

O esforço de integração ensino-serviço segue os seguintes parâmetros: envolvimento da comunidade como espaço social participativo; articulação do curso com os conselhos de saúde e instâncias gestoras do SUS; enfoque epidemiológico de risco e necessidades de saúde da população; inclusão do curso no cuidado de saúde em todos os níveis de atenção; ajuste do cronograma do curso à lógica dos serviços; definição de agenda integrada, viabilizando o estabelecimento de fluxo para referência e contra referência.

Aponta-se também a importância de adoção de conteúdos curriculares relativos às políticas públicas de saúde, evidenciando os princípios do SUS na formação; processo de trabalho em saúde bucal com referencial no trabalho em equipe; IES como espaço de educação permanente para os profissionais de saúde dos serviços; utilização de espaços do SUS como cenários de aprendizagem; enfoque na humanização do cuidado e trabalho em Redes de Atenção.

Para as atividades práticas do curso de graduação em Odontologia que envolvem a integração do curso com o sistema local e regional de saúde/SUS é essencial a obediência à proporção mínima de docentes por alunos, sendo um docente para 12 (doze) alunos nos estágios supervisionados. Na supervisão à assistência odontológica, nos componentes curriculares que envolvem atividades/aulas/procedimentos odontológicos em clínicas de ensino, é necessário considerar os seguintes critérios de relação alunos/docente:

- Não atende: um docente para oito unidades de atendimento, constituída no máximo com dois alunos trabalhando a quatro mãos.

- Insuficiente: um docente para sete unidades de atendimento, constituída no máximo com dois alunos trabalhando a quatro mãos.

- Suficiente: um docente para seis unidades de atendimento, constituída no máximo com dois alunos trabalhando a quatro mãos. 
- Muito bom: um docente para cinco unidades de atendimento, constituída no máximo com dois alunos trabalhando a quatro mãos.

- Excelente: um docente para quatro unidades de atendimento, constituída no máximo com dois alunos trabalhando a quatro mãos.

\section{DOCUMENTOS NECESSÁRIOS:}

$\checkmark$ DCN dos cursos de graduação em Odontologia;

$\checkmark$ PDI;

$\checkmark$ Resolução 350/CNS/2005;

$\checkmark$ PPC;

$\checkmark$ Convênios e parcerias firmadas com instituições vinculadas ao SUS ou com o SUS;

$\checkmark$ Relatórios de atendimentos aos usuários pelos alunos, portfolios, prontuários;

$\checkmark$ Quadro de distribuição dos docentes nas práticas com informativo do número de alunos em cada grupo prático.

\section{EVIDÊNCIAS PARA COMPROVAÇÃO:}

$\checkmark$ Processo de trabalho em saúde bucal desenvolvido no âmbito do curso e nos serviços de saúde permitindo o efetivo trabalho em equipe de saúde bucal, assim como a articulação com os outros profissionais de saúde;

$\checkmark$ Elementos que indicam o papel da Instituição de Educação Superior como espaço de educação permanente para os profissionais de saúde dos serviços;

$\checkmark$ Concepção do PPC em parceria e/ou com compromissos assumidos com os gestores locais do SUS (loco regional);

$\checkmark$ Proporção de docentes por alunos nos estágios supervisionados, nas atividades práticas laboratoriais e na supervisão da assistência odontológica;

$\checkmark$ Desenvolvimento das Competências Gerais previstas nas DCN dos cursos de graduação em Odontologia;

$\checkmark$ Compromisso do curso com a oferta de residências e especializações de acordo com as necessidades de saúde e do sistema de saúde;

$\checkmark$ Contrapartida das instituições privadas que utilizam instituições públicas como campo de ensino em serviço;

$\checkmark$ Aspectos fundamentais para formação com enfoque na humanização do cuidado;

$\checkmark$ Inserção dos estudantes de Odontologia em equipes multidisciplinares e multiprofissionais em diferentes cenários do SUS, com nível de complexidade crescente.

\section{Atividades práticas de ensino para áreas da saúde}

As atividades práticas de ensino de Odontologia se relacionam às competências específicas do curso, conforme DCN dos cursos de graduação em Odontologia e o PPC, em vinculação direta com a competência geral de atenção à saúde e atuação interprofissional. Esta competência indica que o profissional deve estar apto a desenvolver ações de prevenção, promoção, proteção e reabilitação da saúde, em nível individual e coletivo, o que implica que as atividades práticas contemplem diferentes níveis de atenção e áreas de atuação da Odontologia para o alcance do perfil profissional expresso no PPC. Tais atividades devem estar asseguradas em diferentes etapas da formação, por meio de integração com a rede de serviços, considerando disponibilidade relativa ao número de alunos, além de apresentar mecanismos de planejamento, acompanhamento e avaliação. 
Considerar o enfoque de atenção básica especialmente nas áreas de clínica Odontológica integral, clínica infantil e saúde coletiva, em unidades básicas de saúde, clínica-escola da instituição, Centro(s) de Especialidade(s) Odontológica(s) ou unidade(s) hospitalar(es), considerando a perspectiva de hierarquização dos serviços de saúde e da atenção Odontológica.

Para as atividades práticas do curso de graduação em Odontologia é essencial a obediência à proporção de docentes por alunos, considerando a relação alunos/docente mínima:

1. Nos estágios supervisionados, um docente para 12 (doze) alunos;

2. Nas atividades práticas laboratoriais, dos conteúdos pré-profissionalizantes, um docente para 15 (quinze) alunos;

3. Na supervisão à assistência odontológica, nos componentes curriculares que envolvem atividades/aulas/procedimentos odontológicos em clínicas de ensino, é necessário considerar os seguintes critérios de relação aluno/docente:

- Não atende: um docente para oito unidades de atendimento, constituída no máximo com dois alunos trabalhando a quatro mãos.

- Insuficiente: um docente para sete unidades de atendimento, constituída no máximo com dois alunos trabalhando a quatro mãos.

- Suficiente: um docente para seis unidades de atendimento, constituída no máximo com dois alunos trabalhando a quatro mãos.

- Muito bom: um docente para cinco unidades de atendimento, constituída no máximo com dois alunos trabalhando a quatro mãos.

- Excelente: um docente para quatro unidades de atendimento, constituída no máximo com dois alunos trabalhando a quatro mãos.

\section{DOCUMENTOS NECESSÁRIOS:}

$\checkmark$ Regulamentos dos laboratórios básicos da saúde, laboratórios profissionalizantes da Odontologia e Clínica-Escola de Odontologia;

$\checkmark$ Regulamento das atividades práticas de ensino de Odontologia;

$\checkmark$ Instrumentos de avaliação das atividades práticas desenvolvidas no curso de Odontologia, como portfólios, baremas, relatórios de práticas;

$\checkmark$ Planejamento de atividades práticas;

$\checkmark$ Procedimentos Operacionais Padrão (POP) dos procedimentos práticos;

$\checkmark$ Roteiros de atividades e aulas práticas;

$\checkmark$ Resolução 350/CNS/2005.

\section{EVIDÊNCIAS PARA COMPROVAÇÃO:}

$\checkmark$ Existência de atividades práticas de ensino que priorizem o enfoque de atenção à saúde;

$\checkmark$ Coerência das atividades práticas com as competências e habilidades previstas nas DCN dos cursos de graduação em Odontologia e no PPC na definição do perfil profissional;

$\checkmark$ Mecanismos de supervisão das atividades de integração entre ensino-serviço-comunidade;

Evidência da atuação interprofissional nas atividades práticas de ensino;

Proporção de docentes por alunos nos estágios supervisionados, nas atividades práticas laboratoriais e na supervisão da assistência odontológica;

$\checkmark$ Laboratórios didáticos especializados do curso de graduação em Odontologia, inclusive Clínicaescola de Odontologia própria da instituição. 


\subsection{CORPO DOCENTE E TUTORIAL DO CURSO DE GRADUAÇÃO EM ODONTOLOGIA}

O corpo docente e tutorial do curso de graduação em Odontologia reúne critérios que demandam especificidades necessárias ao desenvolvimento do PPC do curso, descritos a seguir.

\section{Núcleo Docente Estruturante - NDE}

O Núcleo Docente Estruturante é o "conjunto de professores, composto por pelo menos cinco docentes do curso, de elevada formação e titulação, contratados em tempo integral ou parcial, que respondem mais diretamente pela concepção, implementação e consolidação do Projeto Pedagógico do Curso (Resolução CONAES N 1, de 17/06/2010)".

É importante observar as competências dos membros do NDE, conforme estabelecido pelo parágrafo único, art. $1^{\circ}$, da Resolução CONAES n ${ }^{\circ} 1 / 2010$, com destaque para as seguintes condições: atuação no desenvolvimento do curso, liderança acadêmica e docência no curso, produção na área de conhecimento do curso. A estratégia de renovação parcial do NDE deve assegurar a continuidade do acompanhamento do curso. Deve-se, ainda, observar a dinâmica de funcionamento e a efetiva atuação do NDE no âmbito do curso (concepção, acompanhamento, consolidação e avaliação do PPC).

Para os cursos de graduação em Odontologia, considera-se critério de excelência que a maioria dos membros do NDE tenham formação em Odontologia e preferencialmente experiência mínima de 3 (três) anos no exercício da docência superior.

\section{DOCUMENTOS NECESSÁRIOS:}

$\checkmark$ Resolução CONAES n ${ }^{\circ}$ 1/2010;

$\checkmark$ Portaria de criação e nomeação do NDE;

$\checkmark$ Relação dos componentes do NDE sendo, no mínimo, 5 docentes do curso em regime de tempo integral ou parcial (mínimo de $20 \%$ em tempo integral); pelo menos $60 \%$ de seus membros possuem titulação stricto sensu e o coordenador do curso como integrante;

$\checkmark \quad$ Atas de reuniões e produtos derivados da atuação do NDE comprovando atuação no acompanhamento, na consolidação e na atualização do PPC, com impacto no sistema de avaliação de aprendizagem na formação do estudante e com análise na adequação do perfil do egresso definido no PPC.

\section{EVIDÊNCIAS PARA COMPROVAÇÃO:}

$\checkmark$ Composição do NDE conforme os requisitos estabelecidos pela Resolução $n^{\circ} 1 / 2010$;

$\checkmark$ Manutenção de parte dos seus membros desde o último ato regulatório do curso;

$\checkmark$ Mecanismos de atuação adotados pelo NDE, considerando as especificidades do curso;

$\checkmark$ Competências dos membros do NDE, conforme estabelecido pelo parágrafo único, art. $1^{\circ}$, da Resolução CONAES n $n^{\circ}$ 1/2010;

$\checkmark$ Estratégia de renovação parcial do NDE, de modo a assegurar a continuidade do acompanhamento do curso;

$\checkmark$ Dinâmica de funcionamento e a efetiva atuação do NDE no âmbito do curso (concepção, acompanhamento, consolidação e avaliação do PPC).

\section{Coordenador de curso}

Para o curso de graduação em Odontologia é essencial que o coordenador seja cirurgião-dentista com experiência mínima de 4 (quatro) a 7 (sete) anos no exercício do magistério superior e de gestão 
acadêmica, somadas. E, que possua no mínimo entre 15 e 20 horas semanais dedicadas exclusivamente à coordenação do curso.

O Coordenador de Curso é o responsável pelo curso, se espera um gestor eficaz, crítico, reflexivo, flexível e proativo que catalisa o comprometimento com a missão e visão da instituição, conhecedor das DCN dos cursos de graduação em Odontologia, PPC, regulamentos, normas e manuais do curso e da instituição.

O coordenador deve se responsabilizar por garantir a construção coletiva e revisão periódica do PPC em conformidade com as DCN dos cursos de graduação em Odontologia. O coordenador deve se envolver com o curso, mantendo uma relação cordial e respeitosa com o corpo docente e corpo discente, mantendo o clima organizacional e motivacional de seu curso. O coordenador é responsável por disseminar o conhecimento das DCN dos cursos de graduação em Odontologia e do PPC para o corpo docente e discente do curso.

Ao Coordenador de Curso compete desempenhar funções como:

- Coordenar e supervisionar as atividades dos professores para implantação das DCN dos cursos de graduação em Odontologia no curso;

- Ser membro ativo e atuante do Colegiado de Curso;

- Ser membro ativo e atuante perante os dirigentes da faculdade;

- Gerenciar e responsabilizar-se pela coordenação dos processos operacionais, pedagógicos e de registro do curso;

- Propor a adoção de estratégias de avaliação e ensino adequadas à educação inclusiva;

- Disseminar princípios e políticas que garantam a inclusão social e assegurar condições de acesso e permanência a estudantes com deficiências.

\section{DOCUMENTOS NECESSÁRIOS}

$\checkmark$ Atas e memórias de reuniões do curso, com corpo dirigente e demais coordenadores da instituição;

$\checkmark$ Regimento Interno da instituição comprovando a representatividade do coordenador de curso nos colegiados superiores;

$\checkmark$ PPC;

$\checkmark$ Relatório de autoavaliação do curso;

$\checkmark$ Indicadores da avaliação do coordenador pelos discentes e docentes e equipe multidisciplinar;

Plano de ações do coordenador.

\section{EVIDÊNCIAS PARA COMPROVAÇÃO}

Envolvimento do coordenador com os docentes, discentes e funcionários do curso;

$\checkmark$ Participação do coordenador nos eventos promovidos pelo curso;

$\checkmark$ Gestão da potencialidade do corpo docente do curso de graduação em Odontologia com integração e melhorias contínuas.

\section{Corpo docente: titulação}

De acordo com o relatório de avaliação quadrienal da Capes, 2017, a Odontologia é a área que possui o maior número de programas de pós-graduação stricto sensu no Brasil, com contingente expressivo e qualificado de mestres e doutores na área. Segundo este mesmo documento, a Odontologia "é uma profissão da área da saúde que, por sua natureza, contempla ações no âmbito clínico-individual e coletivo. Contempla ainda princípios tecnológicos e de inovação que interagem com aspectos biomecânicos, físico-químicos e comportamentais que naturalmente a torna de amplitude multi e interdisciplinar".

Para o ensino do curso de graduação em Odontologia, é necessário que no mínimo entre 50\% e 
$75 \%$ do corpo docente possuam titulação obtida em programa de pós-graduação stricto sensu e, no mínimo, entre $20 \%$ e $35 \%$ possuam doutorado.

\section{DOCUMENTOS NECESSÁRIOS:}

$\checkmark$ Pastas individuais com documentação de cada docente do curso;

$\checkmark$ Cópia (frente e verso) da ata (considerar até 12 meses da data da defesa), diploma ou certificado da titulação;

$\checkmark$ Revalidação dos diplomas de mestrado e doutorado obtidos no exterior, quando existentes;

$\checkmark$ Relação dos docentes do curso, para o ensino de excelência $70 \%$ do corpo docente com formação de pósgraduação stricto sensu e, no mínimo, 35\% com doutorado;

$\checkmark$ Atas e memórias de reuniões dos professores;

$\checkmark$ Planos de ensino das disciplinas;

$\checkmark$ Relatórios de atividades desenvolvidas nas disciplinas;

$\checkmark$ Processos de avaliação do ensino-aprendizagem nas disciplinas.

\section{EVIDÊNCIAS PARA COMPROVAÇÃO:}

$\checkmark$ Atuação do corpo docente na análise dos conteúdos dos componentes curriculares, abordando a relevância para a atuação profissional e acadêmica do discente;

$\checkmark$ Atuação do corpo docente para fomentar o raciocínio crítico com base na literatura atualizada e acesso a conteúdos de ponta da Odontologia, relacionando-os aos objetivos das disciplinas e ao perfil do egresso;

$\checkmark$ Incentivo do corpo docentes para produção de conhecimento dos alunos por meio de grupos de estudos ou de pesquisa e publicação.

\section{Regime de trabalho do docente}

Entende-se por regime de trabalho o modo de inserção e vínculo dos docentes do curso com a instituição e deve integrar o tempo de dedicação seja horista, em tempo parcial ou integral, de acordo com contrato de trabalho ou portaria de nomeação.

Para o ensino do curso de graduação em Odontologia, é necessário que no mínimo entre $60 \%$ e $70 \%$ dos docentes possuam carga horaria dedicada ao atendimento de discentes, planejamento didático, preparação e correção de avaliações, participação no colegiado e orientação, sendo a carga horária para estas atividades não computada na carga horária de sala de aula do docente, no mínimo de $10 \%$ da carga horária de sala de aula do docente do docente.

\section{DOCUMENTOS NECESSÁRIOS:}

$\checkmark \quad$ Art. 52 da Lei 9394 de 1996;

$\checkmark \quad$ Atas e memórias de reuniões dos professores;

$\checkmark$ Pastas individuais com documentação para cada docente do curso;

$\checkmark \quad$ Plano de Cargo e Carreira do Docente protocolado no Ministério do Trabalho;

$\checkmark \quad$ Planos de ensino das disciplinas;

$\checkmark$ Processos de avaliação do ensino-aprendizagem nas disciplinas;

$\checkmark$ Relação dos docentes do curso, para o ensino de excelência 80\% dos docentes devem possuir carga horaria dedicada ao atendimento de discentes, planejamento didático, preparação e correção de avaliações, participação no colegiado, sendo a carga horária destas atividades não computada na carga horária de sala de aula do docente;

$\checkmark$ Relatórios de atividades desenvolvidas nas disciplinas;

$\checkmark$ Documentação sobre as atividades dos professores em registros individuais de atividade docente.

\section{EVIDÊNCIAS PARA COMPROVAÇÃO:}

$\checkmark$ Atendimento às demandas integrais do curso por parte do corpo docente, considerando a dedicação à docência, atendimento aos discentes, participação no colegiado, planejamento didático, preparação e correção das avaliações;

$\checkmark$ Uso da documentação sobre as atividades dos professores em registros individuais de atividade docente para o planejamento e gestão com vistas a melhorias contínuas. 


\section{Experiência profissional do docente}

Refere-se ao exercício profissional, traduzido na dimensão temporal de atuação profissional, que retrata experiência no mundo do trabalho, exceto a experiência acadêmica no magistério superior. Para o ensino do curso de graduação em Odontologia, é necessário que no mínimo entre 50\% e 60\% dos docentes possuam experiência profissional de 3 anos.

\section{DOCUMENTOS NECESSÁRIOS:}

$\checkmark$ Currículo dos docentes documentado;

$\checkmark$ Documento comprobatório da experiência profissional dos docentes, para um curso de excelência, pelo menos $80 \%$ de seus docentes com 3 anos no mundo do trabalho em Odontologia, que os permitem apresentar exemplos contextualizados com relação a problemas práticos de aplicação da teoria ministrada em diferentes unidades curriculares, exceto a experiência acadêmica no magistério superior.

\section{EVIDÊNCIAS PARA COMPROVAÇÃO:}

$\checkmark$ Atualização do corpo docente com relação à interação conteúdo e prática;

$\checkmark$ Promoção da compreensão da aplicação da interdisciplinaridade no contexto laboral;

$\checkmark$ Abordagem do conteúdo e a profissão odontológica pelo corpo docente com base na análise das competências previstas no PPC.

\section{Experiência no exercício da docência superior}

Refere-se ao exercício do magistério superior traduzido na dimensão temporal de atuação docente que retrata a experiência deste professor para o exercício da docência superior. Para o ensino do curso de graduação em Odontologia, é necessário que no mínimo entre 50\% e $60 \%$ de seus docentes possuam experiência de exercício no magistério superior de 3 anos.

\section{DOCUMENTOS NECESSÁRIOS:}

$\checkmark$ Currículo documentado dos docentes;

$\checkmark$ Cópia da carteira profissional ou Portaria de Nomeação;

$\checkmark$ Documento comprobatório da experiência acadêmica no magistério superior, para um curso de excelência pelo menos $80 \%$ de seus docentes possuem experiência docente mínima de 3 anos.

\section{EVIDÊNCIAS PARA COMPROVAÇÃO:}

$\checkmark$ Ações do corpo docente que permitem identificar as dificuldades dos discentes, expor o conteúdo em linguagem apropriada à turma, com contextualização apropriada dos conteúdos por meio de exemplos;

Elaboração de atividades específicas para a promoção da aprendizagem do discente com dificuldades e avaliações diagnósticas formativas e somativas, usando estes resultados para redefinição de sua prática docente;

$\checkmark$ Liderança e reconhecimento da sua produção intelectual.

\section{Atuação do colegiado de curso ou equivalente}

Entende-se o colegiado de curso a instância de gestão, presidido pelo coordenador do curso e constituído por representantes docentes de diferentes áreas do conhecimento (básicas e específicas), discentes e técnico-administrativos; com o objetivo de resolução de questões relativas ao curso que vão desde as necessidades docentes e discentes até a avaliação, resolução e encaminhamento de 
documentos relativos ao curso como um todo. Compete ainda, a esta instância gestora, a instituição de periodicidade das reuniões com seus respectivos registros e as devidas deliberações.

O funcionamento do colegiado do curso de graduação em Odontologia deve estar contemplado no Regimento Interno da IES ou Estatuto Institucional.

\begin{tabular}{|c|c|}
\hline $\begin{array}{l}\text { DOCUMENTOS NECESSÁRIOS: } \\
\checkmark \text { PPC; } \\
\checkmark \text { Instrumento Institucional de Referência ou } \\
\text { Nomeação dos docentes, discentes e } \\
\text { representações técnico-administrativas para } \\
\text { composição do colegiado; } \\
\checkmark \text { Regimento ou Estatuto Institucional; } \\
\checkmark \text { Parecer CONAES n. } 04 \text { de 2010; } \\
\checkmark \quad \text { Atas de Reuniões ou registros do colegiado do } \\
\text { curso; } \\
\checkmark \quad \text { Fluxo de encaminhamento das decisões do } \\
\text { colegiado; } \\
\checkmark \text { Sistema de suporte ao registro, acompanhamento } \\
\text { e execução de seus processos e decisões; } \\
\checkmark \text { Registros da avaliação periódica do desempenho } \\
\text { do colegiado para implementação ou ajuste de } \\
\text { práticas de gestão do curso de graduação em } \\
\text { Odontologia. }\end{array}$ & $\begin{array}{l}\text { EVIDÊNCIAS PARA COMPROVAÇÃO: } \\
\checkmark \text { Participação de docentes e discentes da área de } \\
\text { Odontologia na composição do colegiado; } \\
\checkmark \text { Participação dos membros do colegiado nas } \\
\text { reuniões promovidas; } \\
\checkmark \text { Periodicidade das reuniões do colegiado; } \\
\checkmark \text { Operacionalização das deliberações do } \\
\text { colegiado; } \\
\checkmark \text { Dinâmica e estratégias de renovação do } \\
\text { colegiado; } \\
\checkmark \text { Avaliação do desempenho do colegiado para } \\
\text { implementação ou ajuste de práticas de gestão do } \\
\text { curso de graduação em Odontologia. }\end{array}$ \\
\hline
\end{tabular}

\section{Produção científica, cultural, artística ou tecnológica.}

Entende-se pelo indicador as atividades desenvolvidas pelos docentes, que tem por objetivo o seu processo formativo, compreendendo produções intelectuais, contribuindo para o desenvolvimento e aperfeiçoamento do professor e do próprio curso.

Em consulta ao Glossário dos Instrumentos de Avaliação Externa do INEP - 2018, encontrase a seguinte definição: "Podem ser considerados como produção científica, cultural, artística e tecnológica: livros, capítulos de livros, material didático institucional, artigos em periódicos especializados, textos completos em anais de eventos científicos, resumos publicados em anais de eventos internacionais, propriedade intelectual depositada ou registrada, produções culturais, artísticas, técnicas e inovações tecnológicas relevantes. Publicações nacionais sem Qualis e regionais também devem ser consideradas como produção, considerando sua abrangência".

\section{DOCUMENTOS NECESSÁRIOS:}

$\checkmark$ Glossário dos Instrumentos de Avaliação Externa do INEP - 2018;

$\checkmark$ Pasta individual com comprovação da produção dos docentes;

$\checkmark$ Políticas institucionais de incentivo à produção intelectual dos docentes.

\section{EVIDÊNCIAS PARA COMPROVAÇÃO:}

$\checkmark$ Funcionamento das políticas institucionais de incentivo à produção intelectual dos docentes;

$\checkmark$ Critérios de análise dos Instrumentos de Avaliações Externas do INEP. 


\subsection{INFRAESTRUTURA DO CURSO DE GRADUAÇÃO EM ODONTOLOGIA}

Excelentes condições de infraestrutura são essenciais na oferta com qualidade dos cursos de graduação em Odontologia, pois possibilitam o adequado desenvolvimento das competências gerais e específicas requeridas nas DCN deste curso.

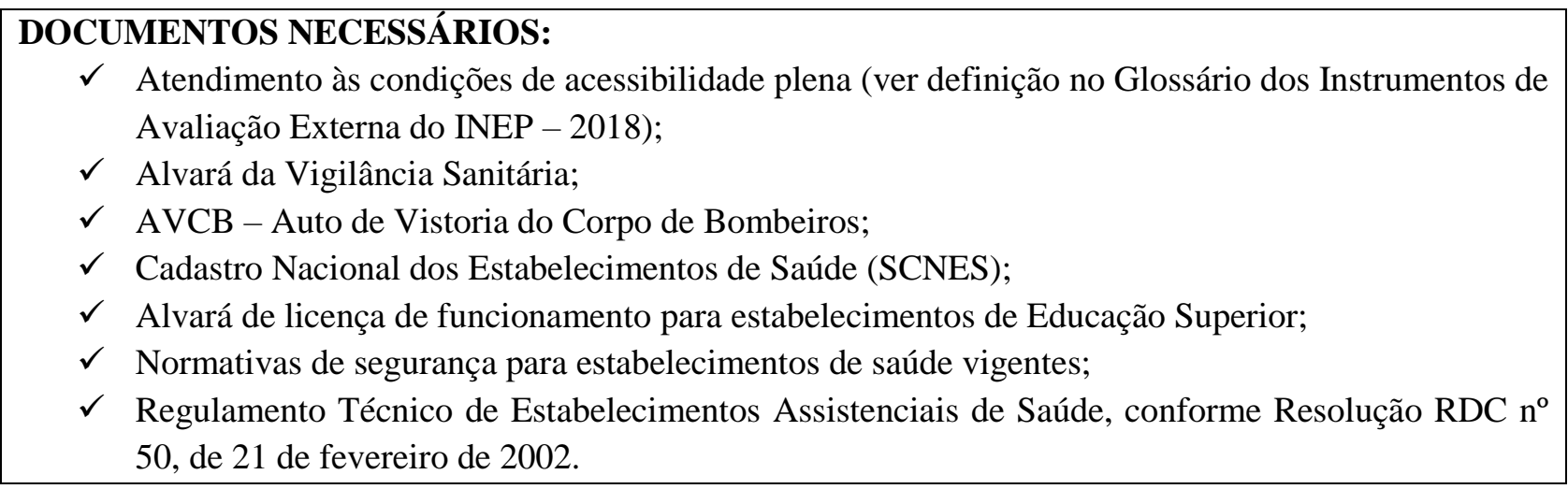

\section{Bibliografia básica e complementar por unidade curricular}

Os planos de ensino dos cursos de graduação em Odontologia devem apresentar uma bibliografia atualizada nos últimos 5 anos e adequada aos conteúdos curriculares propostos, sendo a abrangência dos títulos indicados nas bibliografias básica e complementar, coerentes com os conteúdos das respectivas unidades curriculares e com a formação generalista almejada para a graduação do cirurgião-dentista, definido no perfil do egresso.

Esta bibliografia precisa estar aprovada pelo NDE do curso de graduação em Odontologia.

Para a bibliografia básica, devem constar no PPC e nos planos de ensino no mínimo três títulos por unidade curricular e a proporcionalidade entre o número de vagas e o número de exemplares do acervo físico. Para um curso de excelência, o número de exemplares deve ser de um exemplar de cada título para cada 10 a 15 vagas anuais.

Para a bibliografia complementar, devem constar no PPC e nos planos de ensino no mínimo três títulos por unidade curricular e a proporcionalidade entre o número de vagas e o número de exemplares do acervo físico, no mínimo dois exemplares de cada título disponíveis no acervo físico.

$\mathrm{Na}$ bibliografia complementar, é preciso constar a indicação de pelo menos um periódico especializado compatível ao conteúdo ministrado na disciplina, além dos títulos indicados na bibliografia complementar.

Em relação ao acervo virtual, de títulos e periódicos, a IES precisa possuir um contrato assinado e vigente, com abrangência da cobertura, especificação das instituições de ensino que tem autorização para acesso e número de usuários autorizados a acessarem este acervo virtual correspondente ao número de vagas anuais do curso. $\mathrm{O}$ acesso ao acervo virtual na biblioteca da IES deve estar disponível para a comunidade acadêmica e corresponder àquelas indicações do PPC e planos de ensino. 


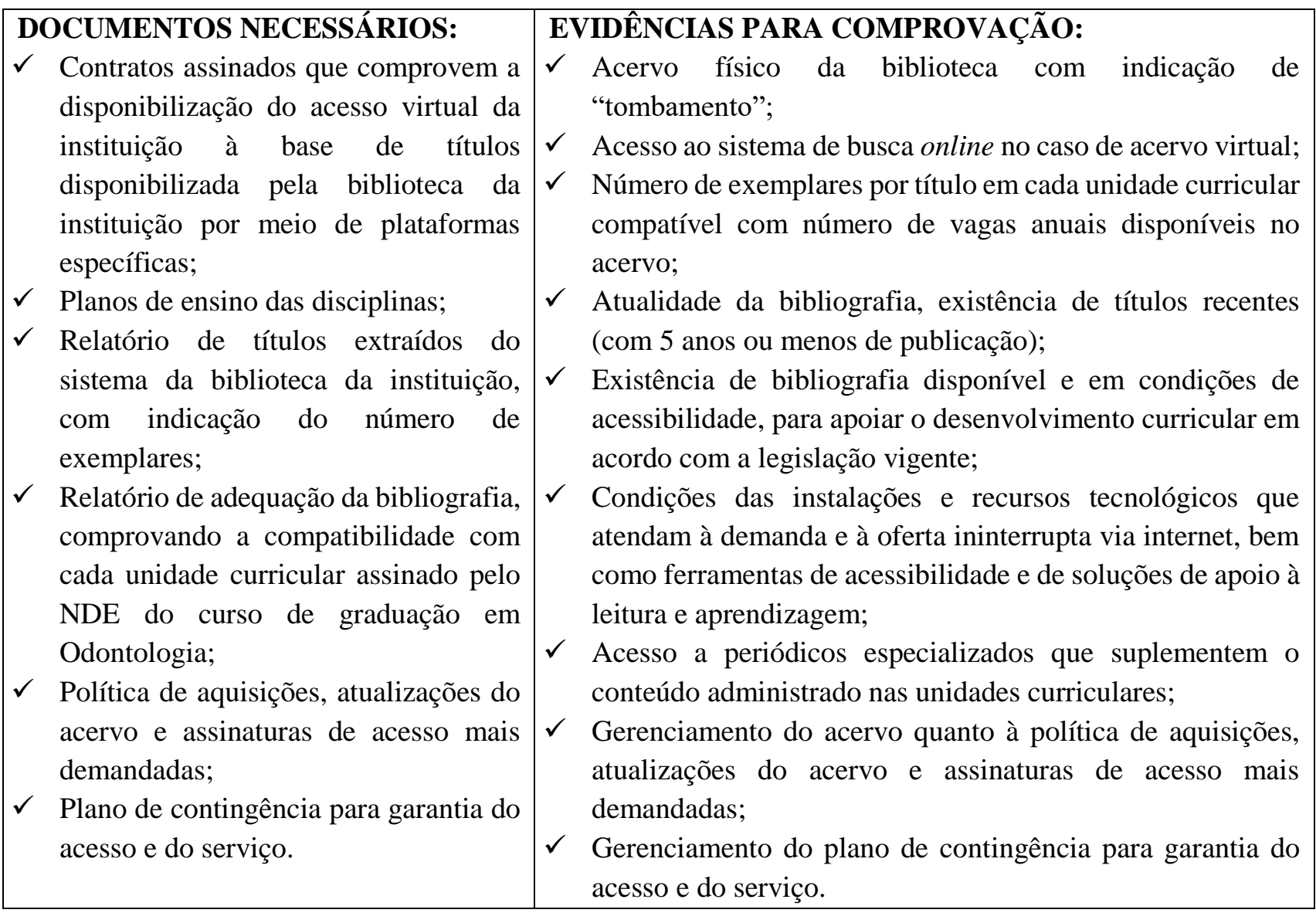

\section{Laboratórios didáticos de formação básica}

Para os cursos de graduação em Odontologia que contemplam no PPC, estes laboratórios didáticos de formação básica tratam-se de todos aqueles que não são considerados como laboratórios didáticos de formação específica, nem laboratórios de ensino ou pesquisa para a área da saúde nem laboratórios de habilidades.

Para as atividades práticas de formação básica do curso de graduação em Odontologia a proporção de docentes por alunos na supervisão das práticas laboratoriais é essencial, ou seja, respeitada a relação entre o número de estudantes e docentes, no mínimo, entendida como um docente para 25 (vinte e cinco) alunos nas atividades práticas laboratoriais de formacão básica.

Os mesmos documentos e evidências para comprovação indicados nos laboratórios didáticos de formação específica, bem como laboratórios de ensino para área da saúde são requeridos nos laboratórios didáticos de formação básica.

\section{Laboratórios didáticos de formação específica}

Os laboratórios didáticos de formação específica para os cursos de graduação em Odontologia incluem obrigatoriamente a clínica-escola de Odontologia própria da IES com ambulatórios odontológicos, ambiente adequado para a radiologia odontológica, laboratório de prótese e de apoio às atividades clínicas do curso que se destinam ao desenvolvimento das atividades práticas das unidades curriculares relacionadas ao desenvolvimento das competências gerais e específicas descritas nas DCN dos cursos de graduação em Odontologia. 
Estes laboratórios deverão apresentar ambientes e recursos que favoreçam o desenvolvimento das competências específicas e dos conteúdos das Ciências Odontológicas que se encontram descritos nas DCN dos cursos de graduação em Odontologia.

Para o curso de graduação em Odontologia considerar a disponibilidade de Clínica-Escola de Odontologia própria da IES com, no mínimo:

- 1 (um) conjunto odontológico completo para cada vaga anual, incluindo os seguintes itens: cadeira odontológica com movimento de ascensão e descida, encosto reclinável, com comando elétrico ou mecânico; unidade suctora acoplada à cadeira, contendo um ou dois sugadores e cuspideira com fonte; dois mochos, equipo contendo refletor, seringa tríplice e apto para as canetas de alta e baixa rotação;

- 1 (um) negatoscópio para cada 15 estudantes ou recursos tecnológicos para visualização de imagem radiográficas (exemplo: monitores) na proporção de 1 (um) para cada 2 estudantes;

- 1 (um) aparelho de raios-X intrabucal para cada 15 conjuntos odontológicos;

Na Clínica-Escola de Odontologia considerar a existência dos seguintes ambientes/laboratórios:

- Laboratório de apoio às atividades clínicas com, no mínimo, recortadores e vibradores de gesso;

- Laboratório de prótese clínica equipado para demonstração da fase laboratorial de prótese unitária, removível e total ou serviço de laboratório de prótese, quando este é terceirizado pela IES, com viabilidade para visitas técnicas dos alunos para esta demonstração;

- Laboratório de interpretação radiográfica com acomodação e número de negatoscópios adequado para atendimento dos estudantes da turma;

- Central de esterilização;

- Almoxarifado - para estoque de materiais odontológicos;

- Setor de regulação e captação de pacientes;

- Recepção e acolhimento de pacientes - sala de espera;

- Infraestrutura para armazenamento de instrumentais/materiais dos estudantes e armários;

- Vestiários.

Para as atividades práticas do curso de graduação em Odontologia nos laboratórios didáticos especializados é obrigatório o acompanhamento e orientação efetivos presenciais in loco por um docente do curso de graduação em Odontologia da própria IES.

Para as atividades práticas do curso de graduação em Odontologia, nos laboratórios didáticos especializados, é essencial a obediência à proporção de docentes por alunos, sendo a relação alunos/docente no mínimo de um docente para 15 (quinze) alunos nas atividades práticas laboratoriais específicas. Na supervisão à assistência odontológica, nos componentes curriculares que envolvem atividades/aulas/procedimentos odontológicos em clínicas de ensino, é necessário considerar a supervisão da assistência odontológica com os seguintes critérios:

- Não atende - Relação aluno/docente - um docente para oito unidades de atendimento, constituída no máximo com dois alunos trabalhando a quatro mãos.

- Insuficiente - Relação aluno/docente - um docente para sete unidades de atendimento, constituída no máximo com dois alunos trabalhando a quatro mãos.

- Suficiente - Relação aluno/docente - um docente para seis unidades de atendimento, constituída no máximo com dois alunos trabalhando a quatro mãos. 
- Muito bom - Relação aluno/docente - um docente para cinco unidades de atendimento, constituída no máximo com dois alunos trabalhando a quatro mãos.

- Excelente - Relação aluno/docente - um docente para quatro unidades de atendimento, constituída no máximo com dois alunos trabalhando a quatro mãos.

\begin{tabular}{|c|c|}
\hline $\begin{array}{l}\text { DOCUMENTOS NECESSÁRIOS: } \\
\checkmark \text { PPC; } \\
\checkmark \text { Planejamento de atividades práticas; } \\
\checkmark \text { Procedimentos Operacionais Padrão (POP) dos } \\
\text { procedimentos práticos; } \\
\checkmark \text { Roteiros de atividades e aulas práticas; } \\
\checkmark \text { Regulamento das atividades práticas de ensino de } \\
\text { Odontologia; } \\
\checkmark \text { Regulamentos de todos os ambientes/laboratórios que } \\
\text { compõem os laboratórios didáticos de formação específica } \\
\text { de Odontologia e da Clínica-Escola de Odontologia; } \\
\checkmark \text { Normas e protocolo de funcionamento, com atendimento } \\
\text { aos itens de segurança e gerenciamento de resíduos; } \\
\checkmark \text { Normas de funcionamento para prestação dos serviços; } \\
\checkmark \text { Políticas de conservação, manutenção e atualização dos } \\
\text { espaços físicos e equipamentos; } \\
\checkmark \text { Tombamento dos equipamentos no Patrimônio da IES; } \\
\checkmark \text { Quadro de distribuição dos docentes nas práticas com } \\
\text { informativo do número de alunos em cada grupo prático; } \\
\checkmark \text { Relação dos recursos humanos de apoio, corpo técnico } \\
\text { específico destes Laboratórios/Clínica-Escola para o } \\
\text { desenvolvimento das diversas atividades previstas para as } \\
\text { atividades práticas definidas nas unidades curriculares; } \\
\checkmark \text { Registros que evidenciem a prestação dos serviços à } \\
\text { comunidade; } \\
\checkmark \text { Registros de informações legais com controle de acesso, } \\
\text { distribuição, utilização de informações e armazenagem de } \\
\text { dados eletrônicos ou não, atendendo as necessidades do } \\
\text { curso obedecendo a normas de caráter ético e legal. }\end{array}$ & $\begin{array}{l}\text { EVIDÊNCIAS PARA COMPROVAÇÃO: } \\
\checkmark \quad \text { Atualização dos equipamentos e a } \\
\text { disponibilidade de insumos; } \\
\checkmark \text { Qualidade, diversidade e disponibilidade } \\
\text { de equipamentos, insumos, materiais e } \\
\text { instrumentais para a demanda do serviço } \\
\text { proposto e número de vagas anuais; } \\
\checkmark \text { Condições de funcionamento e de } \\
\text { atendimento aos estudantes; } \\
\checkmark \text { Proporção de docentes por alunos nos } \\
\text { estágios supervisionados, nas atividades } \\
\text { práticas laboratoriais e na supervisão da } \\
\text { assistência odontológica; } \\
\checkmark \text { Ações de conservação, manutenção e } \\
\text { atualização dos espaços físicos e } \\
\text { equipamentos; } \\
\checkmark \text { Recursos humanos de apoio com corpo } \\
\text { técnico próprio e específico em número } \\
\text { suficiente para o desenvolvimento das } \\
\text { diversas atividades previstas para as } \\
\text { atividades práticas definidas nas unidades } \\
\text { curriculares. }\end{array}$ \\
\hline
\end{tabular}

\section{Laboratórios de ensino para a área da saúde}

Para os cursos de graduação em Odontologia são considerados laboratórios de ensino para a área da saúde ou ensino do ciclo básico da saúde, os espaços físicos específicos e multidisciplinares e seus respectivos equipamentos/ materiais utilizados para a aprendizagem das unidades curriculares das Ciências Biológicas e da Saúde, incluindo os conteúdos (teóricos e práticos) de base moleculares e celulares dos processos normais e alterados, da estrutura e função dos tecidos, órgãos, sistemas e aparelhos. 
Para tanto, o curso de graduação em Odontologia deve ter disponível para as aulas/ atividades práticas dos estudantes destas unidades curriculares:

- Laboratório de Morfologia para os conteúdos curriculares de Citologia e Biologia Celular, Embriologia, Histologia e Anatomia;

- Laboratório de Microbiologia;

- Laboratório de Bioquímica;

- Laboratório de Fisiologia;

- Laboratório de Farmacologia;

- Laboratório de Patologia;

- Laboratório de Imunologia.

Em cada um deste laboratórios, mesmo que sejam adotados laboratórios multifuncionais aonde se agreguem 2 ou 3 áreas de conhecimento das Ciências Biológicas e da Saúde, devem estar disponíveis os equipamentos e insumos específicos para cada área de conhecimento respectiva citada, serviço técnico e dimensão apropriada para comportar no mínimo 25 alunos, confortavelmente instalados para realização das aulas/ atividades.

Para o curso de graduação em Odontologia considerar além das peças, lâminas e objetos de aprendizagem das unidades curriculares das Ciências Biológicas e da Saúde do corpo humano, também a existência de peças, lâminas e objetos de aprendizagem específicos das Ciências Biológicas e da Saúde aplicadas à Odontologia.

Para as atividades práticas do curso de graduação em Odontologia é essencial a obediência à proporção de docentes por alunos, sendo no mínimo um docente para 25 (vinte e cinco) alunos, nestes Laboratórios de ensino para a área da saúde.

\section{DOCUMENTOS NECESSÁRIOS:}

$\checkmark$ PPC;

$\checkmark$ Planejamento de atividades práticas;

$\checkmark$ Procedimentos Operacionais Padrão (POP) dos procedimentos práticos;

$\checkmark$ Roteiros de atividades e aulas práticas;

$\checkmark$ Regulamento das atividades práticas de ensino das Ciências Biológicas e da Saúde;

$\checkmark$ Regulamentos de todos ambientes/laboratórios que compõem os Laboratórios de ensino para a área da saúde;

$\checkmark$ Políticas e ações de conservação, manutenção e atualização dos espaços físicos e equipamentos;

$\checkmark$ Relação dos recursos e insumos disponibilizados para atender as atividades dos planos de ensino das unidades curriculares das Ciências Biológicas e da Saúde;

$\checkmark$ Quadro de distribuição dos docentes nas práticas com informativo do número de alunos em cada grupo prático;

\section{EVIDÊNCIAS PARA COMPROVAÇÃO:}

$\checkmark$ Ações de conservação, manutenção e atualização dos espaços físicos e equipamentos;

$\checkmark$ Compatibilidade entre a quantidade de laboratórios de ensino e o número de vagas anuais do curso de graduação em Odontologia e demais cursos da área da saúde que utilizam estes mesmos laboratórios;

$\checkmark$ Compatibilidade entre os laboratórios e disciplinas, conteúdos e metodologias previstos no PPC;

$\checkmark$ Condições de acessibilidade plena, atualização dos equipamentos e disponibilidade de insumos;

$\checkmark$ Condições de funcionamento e de atendimento aos estudantes;

$\checkmark$ Instalação e operacionalização dos equipamentos de segurança;

$\checkmark$ Ações de conservação, manutenção e atualização dos espaços físicos e equipamentos;

$\checkmark$ Proporção de docentes por alunos nas atividades práticas laboratoriais;

$\checkmark$ Qualidade, diversidade e disponibilidade de equipamentos, insumos, materiais e instrumentais 


\begin{tabular}{|c|c|}
\hline $\begin{array}{l}\text { Relação dos recursos humanos de apoio, corpo } \\
\text { técnico específico destes Laboratórios para o } \\
\text { desenvolvimento das diversas atividades } \\
\text { previstas para as atividades práticas definidas nas } \\
\text { unidades curriculares das Ciências Biológicas e } \\
\text { da Saúde; } \\
\text { Normas de funcionamento para prestação dos } \\
\text { serviços. }\end{array}$ & $\begin{array}{l}\text { para atender as atividades dos planos de ensino das } \\
\text { unidades curriculares das Ciências Biológicas e da } \\
\text { Saúde e número de vagas anuais dos cursos da saúde } \\
\text { que utilizam estes laboratórios; } \\
\checkmark \quad \text { Recursos humanos de apoio com corpo técnico } \\
\text { próprio e específico em número suficiente para o } \\
\text { desenvolvimento das diversas atividades previstas } \\
\text { para as atividades práticas definidas nas unidades } \\
\text { curriculares; } \\
\checkmark \quad \text { Recursos tecnológicos comprovadamente } \\
\text { inovadores; } \\
\checkmark \text { Tombamento dos equipamentos no Patrimônio da } \\
\text { IES. }\end{array}$ \\
\hline
\end{tabular}

\section{Laboratórios de habilidades}

Para os cursos de graduação em Odontologia são considerados laboratórios de habilidades os espaços destinados ao ensino dos conteúdos técnicos, metodológicos e dos meios e instrumentos inerentes às práticas pré-profissionalizantes da Odontologia.

Deve-se considerar a capacitação dos estudantes nas diversas habilidades da atividade odontológica, considerando a existência de:

- Laboratório pré-clínico de técnicas odontológicas com um equipo simulador odontológico completo para cada duas vagas anuais, incluindo os seguintes itens: um mocho, um equipo contendo refletor, seringa tríplice e apto para as canetas de alta e baixa rotação, um simulador com cabeça e tronco para manequim odontológico;

- Laboratório de prótese clínica equipado para demonstração da fase laboratorial de prótese unitária, removível e total ou serviço de laboratório de prótese, quando este é terceirizado pela IES, com viabilidade para visitas técnicas dos alunos para esta demonstração;

- Laboratório de interpretação radiográfica com acomodação e número de negatoscópios ou recurso tecnológico para visualização de imagens radiográficas (exemplo: monitores) na proporção mínima de um negatoscópio ou um monitor para cada 2 alunos.

Para as atividades práticas do curso de graduação em Odontologia é essencial a obediência à relação alunos/docente mínima de um docente para 15 (quinze) alunos nas atividades práticas laboratoriais.

\begin{tabular}{|l|l|l|}
\hline DOCUMENTOS NECESSÁRIOS: & $\begin{array}{l}\text { EVIDÊNCIAS PARA COMPROVAÇÃO: } \\
\checkmark\end{array}$ \\
$\checkmark$ & $\begin{array}{l}\text { PPC; } \\
\text { Ações de conservação, manutenção e atualização } \\
\text { dos espaços físicos e equipamentos; }\end{array}$ \\
& $\begin{array}{l}\text { laboratório; funcionamento e segurança do } \\
\checkmark\end{array}$ \\
$\begin{array}{l}\text { Planejamento de atividades práticas; } \\
\checkmark\end{array}$ & $\checkmark \begin{array}{l}\text { Compatibilidade entre a quantidade de } \\
\text { laboratórios de habilidades e o número de vagas }\end{array}$ \\
$\begin{array}{l}\text { atualização dos espaços físicos e equipamentos; } \\
\text { Tombamento dos equipamentos no patrimônio } \\
\text { da IES; }\end{array}$ & $\checkmark \begin{array}{l}\text { anuais do curso de graduação em Odontologia; } \\
\text { Compatibilidade entre os laboratórios e } \\
\text { disciplinas, conteúdos e metodologias previstos } \\
\text { no PPC; }\end{array}$ \\
\hline
\end{tabular}




\begin{tabular}{|c|c|}
\hline $\begin{array}{l}\text { Procedimentos Operacionais Padrão (POP) dos } \\
\text { procedimentos práticos; } \\
\text { Quadro de distribuição dos docentes nas práticas } \\
\text { com informativo do número de alunos em cada } \\
\text { grupo prático; } \\
\text { Regulamento das atividades práticas pré- } \\
\text { profissionalizantes das Ciências Odontológicas; } \\
\text { Regulamentos de todos os } \\
\text { ambientes/laboratórios que compõem os } \\
\text { Laboratórios de habilidades; } \\
\text { Relação dos recursos e insumos disponibilizados } \\
\text { para atender as atividades dos planos de ensino } \\
\text { das unidades curriculares das Ciências } \\
\text { Odontológicas Pré-profissionalizantes; } \\
\text { Relação dos recursos humanos de apoio, corpo } \\
\text { técnico específico destes Laboratórios para o } \\
\text { desenvolvimento das diversas atividades } \\
\text { previstas para as atividades práticas definidas nas } \\
\text { unidades curriculares das Ciências } \\
\text { Odontológicas Pré-profissionalizantes; } \\
\text { Roteiros de atividades e aulas práticas. }\end{array}$ & $\begin{array}{l}\checkmark \text { Condições de funcionamento e de atendimento } \\
\text { aos estudantes; } \\
\checkmark \quad \text { Instalação e operacionalização dos equipamentos } \\
\text { de segurança; } \\
\checkmark \quad \text { Proporção de docentes por alunos nas atividades } \\
\text { práticas laboratoriais; } \\
\checkmark \quad \text { Qualidade, diversidade e disponibilidade de } \\
\text { equipamentos, insumos, materiais e } \\
\text { instrumentais para atender as atividades dos } \\
\text { planos de ensino das unidades curriculares das } \\
\text { Ciências Odontológicas Pré-Profissionalizantes } \\
\text { e número de vagas anuais dos cursos da saúde } \\
\text { que utilizam estes laboratórios; } \\
\checkmark \quad \text { Recursos humanos de apoio com corpo técnico } \\
\text { próprio e específico em número suficiente para o } \\
\text { desenvolvimento das diversas atividades } \\
\text { previstas para as atividades práticas definidas nas } \\
\text { unidades curriculares; } \\
\checkmark \text { Recursos tecnológicos comprovadamente } \\
\text { inovadores. }\end{array}$ \\
\hline
\end{tabular}

\section{Unidades hospitalares e complexo assistencial conveniados}

As DCN do curso de graduação em Odontologia preveem formação que assegure a integralidade das ações do cuidado e, portanto, devem contemplar a diversidade de cenários do trabalho do cirurgião-dentista nos diferentes níveis assistenciais. Logo, o complexo assistencial conveniado deve atender a todas as demandas para desenvolvimento das competências e habilidades na formação do egresso em contextos reais e em equipes interprofissionais.

\begin{tabular}{|c|c|}
\hline $\begin{array}{l}\text { DOCUMENTOS NECESSÁRIOS: } \\
\checkmark \text { PPC; } \\
\checkmark \text { Convênio assinado com unidades } \\
\text { hospitalares e complexo assistencial; } \\
\checkmark \text { Descrição do sistema de referência e } \\
\quad \text { contrarreferência. }\end{array}$ & $\begin{array}{l}\text { EVIDÊNCIAS PARA COMPROVAÇÃO: } \\
\checkmark \text { Período de vigência dos convênios assinados entre a IES } \\
\text { com Unidades hospitalares e complexo assistencial; } \\
\checkmark \text { Unidade (s) hospitalar(es) e complexo assistencial em } \\
\text { relação às condições para a formação dos egressos; } \\
\checkmark \text { Diversidade e complexidade das atividades pedagógicas e } \\
\text { assistenciais propiciadas no âmbito destes convênios; } \\
\checkmark \text { Funcionamento do sistema de referência e } \\
\text { contrarreferência; } \\
\checkmark \text { Práticas interdisciplinares e interprofissionais na atenção à } \\
\text { saúde; } \\
\checkmark \text { Aderência das atividades pedagógicas e assistenciais } \\
\text { desenvolvidas nas unidades hospitalares e no complexo } \\
\text { assistencial à lei do exercício profissional de Odontologia. }\end{array}$ \\
\hline
\end{tabular}

